\title{
A review identifying the effectiveness of minimum quantity lubrication (MQL) during conventional machining
}

\author{
B. Boswell, M.N. Islam, Ian J. Davies, Y. R. Ginting and Ai Keem Ong \\ Department of Mechanical Engineering, Curtin University, GPO Box U1987, Perth, \\ WA 6845, Australia
}

\begin{abstract}
Government legislation and public opinion are the main drivers behind the movement of manufacturing companies towards sustainable production. Fundamentally, companies want to avoid future financial penalties and the industry is therefore under pressure to adapt new techniques and practices in order to become environmentally friendly. The cost efficiency of metal cutting operations is highly dependent on accuracy, excellent surface finish and minimised tool wear and, to this end, has traditionally made abundant use of cutting fluid in machining operations. However, these cutting fluids have been a major contributor to environmental and health issues. In recent years an enormous effort to eradicate these adverse effects has been made with one important focus being the implementation of minimum quantity lubrication (MQL). In the present work the authors have reviewed the current state of the art in MQL with a particular focus on drilling, turning, milling and grinding machining operations. Overall it is concluded that MQL has huge potential as a substitute for conventional flood cooling.
\end{abstract}

Keywords: Flank wear, minimum quantity lubrication, sustainability, effectiveness, consumption, financial penalties.

Corresponding author: Nazrul Islam, Department of Mechanical Engineering, Curtin University, GPO Box U1987, Perth, WA 6845, Australia (e-mail: m.n.islam@curtin.edu.au; tel: +61 892663777 ; fax: +61 892662681 ) 


\subsection{Introduction}

The effectiveness of traditional machining processes is highly dependent on the presence of cutting fluid in order to decrease cutting temperatures and cutting forces. Unfortunately, these cutting fluids are well known to cause environmental and health issues. In an effort to eradicate these adverse effects, several avenues of research have been explored with one major focus being that of minimum quantity lubrication (MQL) which is also known as near-dry machining (NDM) [1, 2] or micro-lubrication [3]. However, the amount of lubricant varies considerably between various studies. For example, according to Tschätsch and Reichelt the range of cutting fluid consumption is between $50 \mathrm{ml} / \mathrm{h}$ to $2 \mathrm{l} / \mathrm{h}$ [4] whereas other studies have reported even lower amounts of 10-100 ml/h [5-7]. Nevertheless, the consumption of cutting fluid is known to be significantly reduced in MQL compared to conventional flood cooling where the typical rate is approximately $1200 \mathrm{l} / \mathrm{h}$ [7]. MQL has been receiving worldwide attention due to its low oil consumption and general provision of excellent machining results. The machining performance under MQL conditions has been reported to be comparable to that of traditional flood cooling, if not better [8-10]. The purpose of this review is to provide readers with a clear understanding of the feasibility of MQL as a substitute for conventional flood cooling in machining operations.

The first use of the phrase "minimum quantity lubrication" in the literature appears to have been by Weck and Koch in 1993 in relation to the lubrication of bearings [11]. Following this, the first research on MQL relating to machining operations was in 1997 for grinding [12] and shortly afterwards for cutting [13]. Figure 1 shows the rapid growth in MQL publications since the early 2000s with more than 100 articles being published during 2015 as compared to just one article in 2000 [14]. The growth in patents related to MQL has also shown a similar trend with the first patents being granted in the late 1990s and more than 400 patents having been granted to the present time. MQL was initially studied in regards to contact lubrication, e.g., roller bearings $[15,16]$ and piston rings $[17,18]$, but since the early 2000 s has tended to focus on lubrication in machining processes. Increasing research has been conducted into its effectiveness when used for difficult-to-machine materials such as titanium with more than eighty articles having been published in this area since 1999 [19]. 


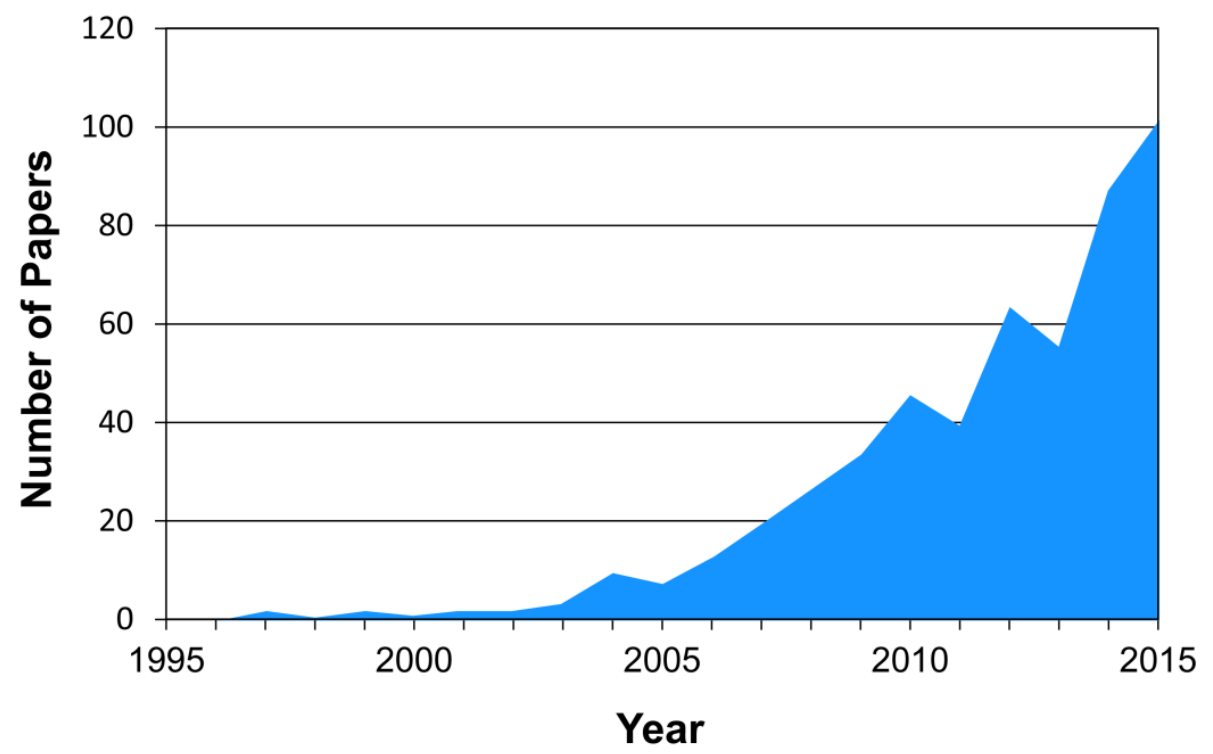

Figure 1: Number of journal papers published on "minimum quantity lubrication" [14].

The increasing interest to further improve MQL has given rise to new technologies that complement the machining process, e.g., the inclusion of nanoparticles in MQL fluids [20, 21] and the combination of cooled air with MQL [22]. More than fifty articles have been published on MQL incorporating nanoparticles since 2008 [23] with a continuing rise in publications which confirms the ever growing attention MQL has received in the past years.

Out of nearly 600 papers considered by the authors during the course of this work, more than half were focussed on the four main types of machining, namely, drilling, turning, milling and grinding. Of these four main categories, grinding was the most popular (29\%) and followed by milling (26\%) and then turning (24\%) and drilling (21\%). This demonstrates that the MQL studies were distributed relatively evenly in terms of machining types, which once again, confirms the high applicability of MQL.

\subsection{Economic concerns}

The high consumption of cutting fluids results in extremely high costs worldwide. For example, the cost of purchasing and disposing of cutting fluids in the U.S. has been estimated at 48 billion dollars per year [24]. In Germany the cost has been estimated at 1 billion German Marks [25] whereas the associated cost in Japan is 71 billion yen per year including 42 billion yen just for disposal costs [26]. The high cost of cutting fluids is further confirmed by claims reported from various companies. For example, it was reported that the management of cutting fluid or 
coolant costs more than four times that of the cutting tools and represents at least $16 \%$ of the product cost $[27,28]$. This surprisingly high price is supported by studies made by different countries including America, Germany and Spain [29]. The factors that contribute to the high cost include system costs, personnel costs for material monitoring and maintenance, in addition to investment costs for splitting plants and water purification [30]. Further costs are also incurred in the process of drying wet chips as recyclers only accept dry chips [27]. Manufacturers who are able to save on cutting fluid costs and its associated equipment, in addition to the production of clean chips, can reap the benefits of extra profits. For example, according to Unist Inc. [31], one of their customers reported that the company earned an extra 10 cents per kilogram of dry chips when compared with wet chips.

In order to achieve lubrication in dry machining conditions, researchers have examined the application of coated cutting tools, with it being agreed that dry machining is possible in the presence of appropriate tool coatings [32, 33]. For example, Dudzinski et al. studied the developments towards dry and high speed machining of Inconel 718 alloy and concluded that, with the application of physical vapour deposition titanium aluminium nitride (PVD (Ti,Al)N) coated tools, dry cutting of Inconel 718 at higher cutting speeds up to $100 \mathrm{~m} / \mathrm{min}$ was achievable [34]. While dry machining is applicable in the turning and milling operations of most materials, dry drilling remains an issue. This is supported by a summary made by Kutz [35] on the applicability of dry machining based on machining processes and workpiece materials. The main problem associated with dry drilling is the clogging of chips in the drill flutes which can result in drill failure. This phenomena was clearly shown in an experiment by Dasch et al. where the absence of a cooling effect during the dry drilling of aluminium produced temperatures in excess of $350{ }^{\circ} \mathrm{C}$, which would soften the aluminium and also compromise many carbon-based coatings [36]. Furthermore, many of the drill flutes eventually became clogged with aluminium and the drilling torque increased leading to drill fracture. Such a result confirmed the significance of heat removal in the machining process. Excessive heat generation was also reported in the case of dry grinding when Hadad and Hadi investigated the surface grinding of S34700 hardened stainless steel and AA6061 aluminium alloy using dry, MQL and conventional flood cooling techniques [37]. A comparison was made with respect to the maximum surface temperature rise for all cooling techniques. In the case of stainless steel, dry machining yielded the highest temperature rise $\left(960^{\circ} \mathrm{C}\right)$ followed by MQL (average of $\left.565^{\circ} \mathrm{C}\right)$ and flood cooling $\left(305^{\circ} \mathrm{C}\right)$. These results have been supported by other research that has identified the difficulty of removing or reducing the generation of heat in dry machining 
conditions. It is these types of concern that have driven manufacturers to investigate various methods for introducing a cooling effect in dry machining such as through MQL.

\subsection{MQL characteristics}

It is important that MQL fluid possesses the following properties due to the requirements for sustainability and low oil consumption:

- Biodegradable

- High lubrication

- High stability

The two most common cutting fluids used in MQL applications are vegetable-based oils and synthetic esters, owing to their superior biodegradability $[6,38,39]$. Khan and Dhar outlined the six main advantages of vegetable-based oils compared with conventional metal working fluids as follows [40]:

(1) The molecules, being long, heavy, and dipolar in nature, create a dense homogeneous and strong lubricating film that gives the vegetable oil a greater capacity to absorb pressure.

(2) The lubricating film layer provided by vegetable oils, being intrinsically strong and lubricious, improves workpiece quality and overall process productivity reducing friction and heat generation.

(3) A higher flash point yields opportunities for increased rates of metal removal as a result of reduced smoke formation and fire hazard.

(4) The higher boiling point and greater molecular weight of vegetable oil results in considerably less loss from vaporization and misting.

(5) Vegetable oils are non-toxic to the environment and biologically inert and do not produce significant organic diseases and toxic effects.

(6) No signs or symptoms of acute or chronic exposure to vegetable oil mist have been reported in humans.

These advantages were reflected in various studies on milling [41], drilling [42, 43], turning [40, 44, 45] and grinding [46]. As for synthetic esters, similar properties were observed including high boiling temperature, flash point and low viscosity, thus leaving a thin film of oil on the workpiece which aids in corrosion resistance [38]. Some studies showed that the 
application of synthetic oil outperformed vegetable and mineral oils [47, 48]. The compatibility of synthetic ester and MQL was clearly shown in a grinding experiment on Ti-6Al-4V titanium alloy conducted by Sadeghi et al. [48]. Using the same machining parameters, it was observed that the application of synthetic oil led to lower grinding forces and better surface quality (Figure 2) compared to the application of vegetable oil.
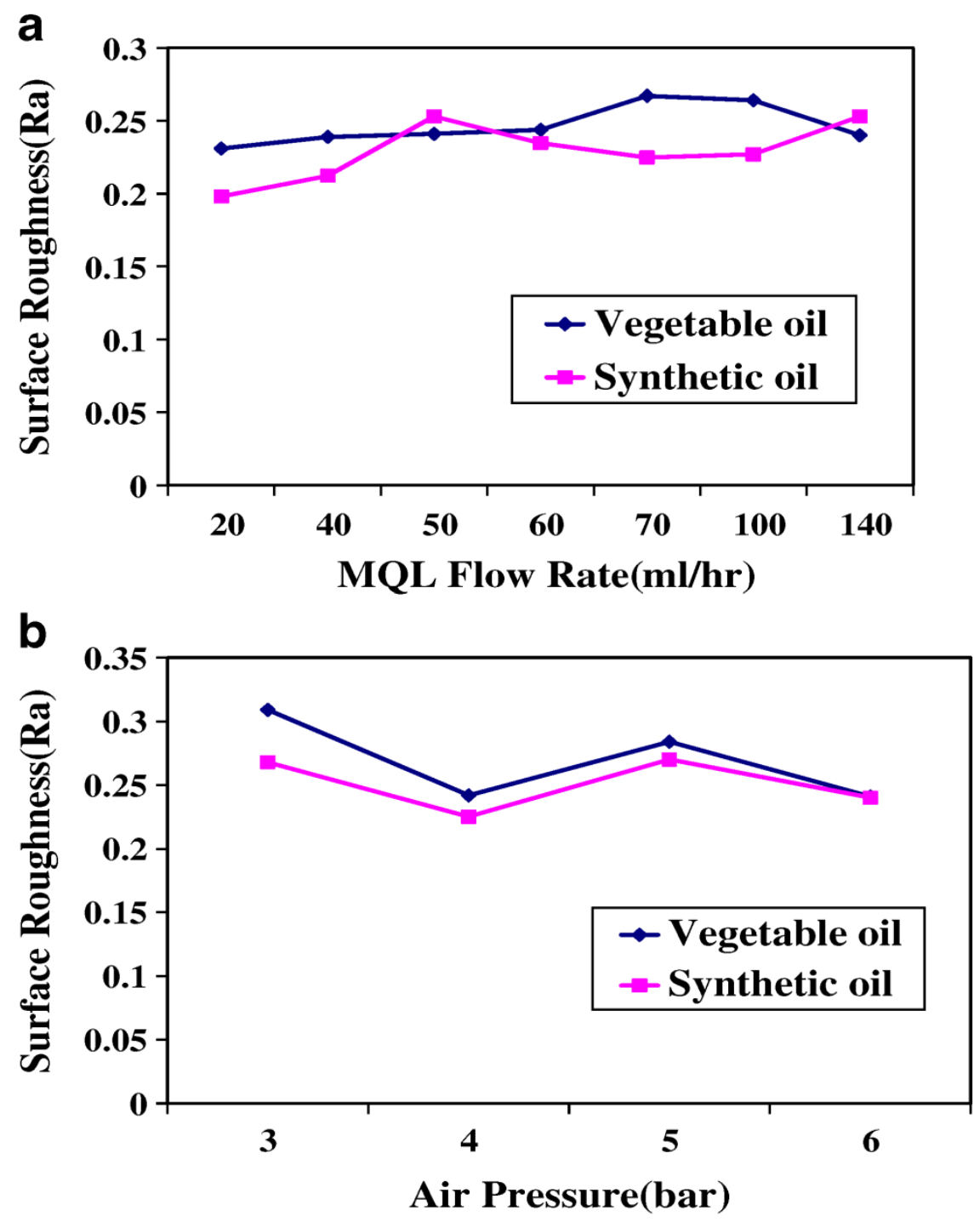

Figure 2: Effect of MQL parameters on the surface roughness of grinded titanium alloy at work speed $=40 \mathrm{~m} / \mathrm{min}$, wheel speed $=15 \mathrm{~m} / \mathrm{s}$, depth of cut $=0.005 \mathrm{~mm}$ and: (a) air pressure $=4$ bar and (b) MQL flow rate $=60 \mathrm{ml} / \mathrm{h}$ [48].

Other than cutting fluid, an extra media is necessary to transport the lubricant effectively into the cutting zone (tool/work interface). The most common media used is pressurized 
atmospheric air with pressures ranging from three to seven bars [27, 48-50]. However, in recent years researchers have ventured into the hybrid effect of cooled air with MQL in order to enhance its cooling ability $[22,51]$. Compared to conventional flood cooling, MQL is a sustainable technique especially with regards to its environmental aspect due to its reduced oil consumption and energy consumption.

\subsection{Types of MQL delivery systems}

Based on selected literature [2, 27, 52], a summary of different types of MQL delivery systems has been presented in Figure 3.

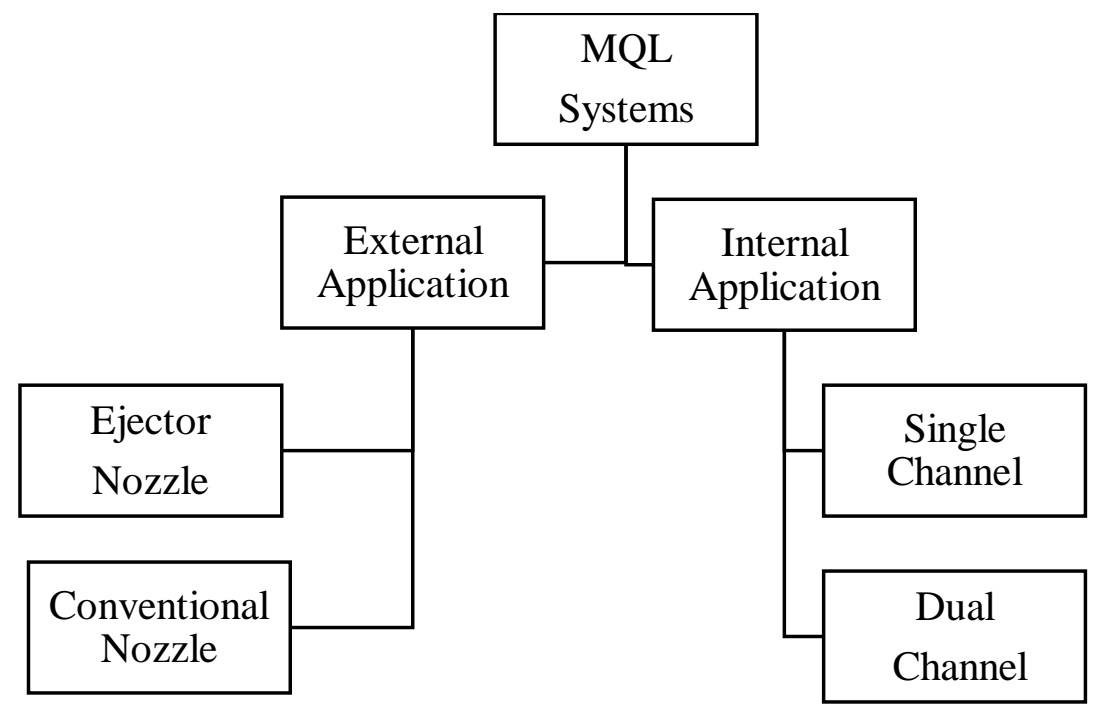

Figure 3: MQL delivery systems.

There are two major delivery methods for MQL - one is an external application and the other is an internal application. In the case of the external application, a mixture of compressed air and oil is fed via an external nozzle to the cutting zone from a chamber. In contrast to this, there are two possible methods for the external application of oil and air or aerosol (Figure 4):

- Ejector nozzle: The compressed air and oil are supplied to the ejector separately and mixing occurs just after the nozzle. 
- Conventional nozzle: The aerosol is prepared in an external atomizer and then transported to a conventional nozzle.

The internal delivery system of MQL is also known as a through-tool application, where the delivery of MQL is made through the spindle. There are two different configurations available (Figure 5):

- Single-channel: The oil and compressed air are mixed before being supplied through the cutting tool to the workpiece/tool zone.

- Dual-channel: The oil and compressed air are delivered in different channels and are only mixed before the holder of the cutting tool.

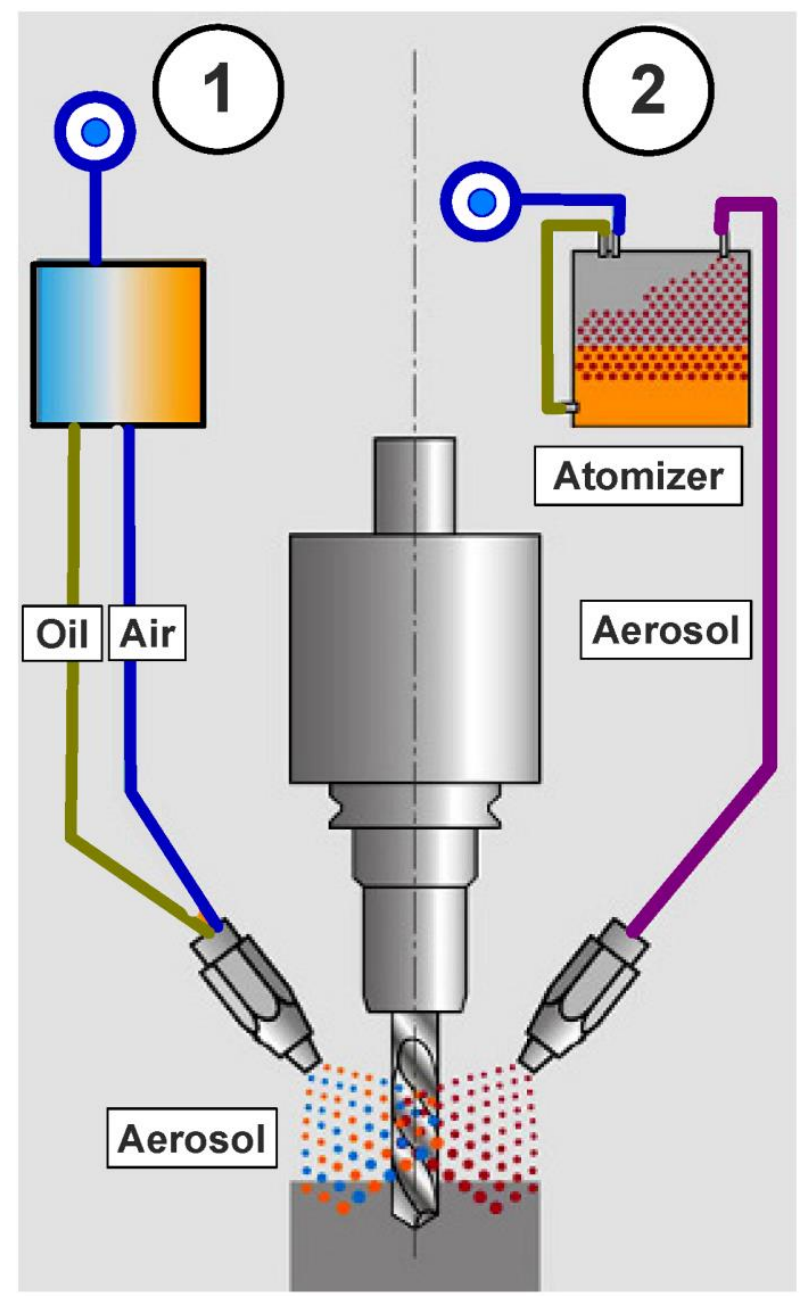

Figure 4: The principles of ejector nozzle and conventional nozzle in MQL external applications as illustrated by Astakhov [2]. 


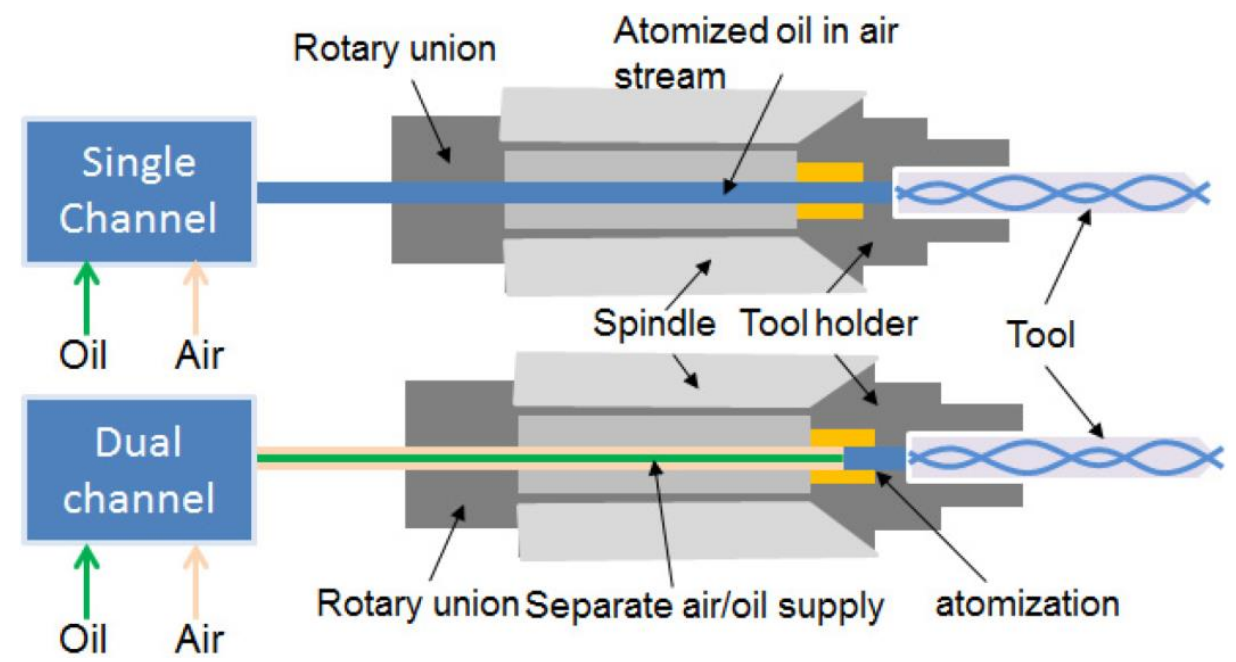

Figure 5: The principles of single channel and dual channel in MQL internal applications [7].

Out of the four combinations mentioned above, the dual-channel internal system was reported to be the ideal configuration, especially for drilling and boring operations [53-55]. For example, Zeilmann and Weingaertner analyzed the drilling temperature of Ti-6Al-4V titanium alloy under MQL conditions using different delivery methods (internal and external) [53]. It was reported that the maximum temperature increase measured in the case of internal MQL was $50 \%$ lower than that of externally applied MQL. The main issue with external application is that the supplied aerosol will not be able to penetrate into the hole during machining. Besides that, as the compressed air and oil are mixed close to the tool in a dual-channel internal system, the supplied aerosol is affected only by the rotation of the spindle for a short distance, providing a better response in discharging the aerosol such as reduced dispersion and dropouts, as well as producing mist with larger droplet sizes when compared to that from an external mixing device [27].

\subsection{Effectiveness of machining with MQL}

Workpiece materials and types of machining process play an important role in determining the effectiveness of a machining performance when MQL is used. Therefore, categorising with respect to material being machined can provide a better comparison of the effectiveness of MQL relative to the process. 


\subsection{Turning and milling of aluminium}

The main problem identified by researchers in the machining of aluminium alloys is material adhesion with the amount of cutting fluid determining the level of material adhesion to the cutting tool surface. Bhowmick studied the application of MQL with aluminium and magnesium alloys and pointed out the presence of such an adhesion issue [9]. It was reported that a large amount of adhered material was observed on the rake, clearance and flank faces of cutting tools during the high speed milling of aluminium-silicon (319 Al) alloy in a dry environment, whereas a moderate amount of adhered material was observed under MQL conditions with flood cooling resulting in the least amount of material adhesion. Similar results were reported by Sreejith in an experiment on turning 6061 aluminium alloy where the amount of material adhering to the cutting tool surface was noted to be higher in MQL machining compared to flood cooling [56]. To solve the above mentioned problem, a more in-depth study on the adhesion of aluminium alloy during machining was conducted by Yoshimura et al. where it was observed that an increase in cutting speed could reduce the amount of adhered material [57].

Another solution proposed by researchers is the application of diamond-like coating (DLC) and diamond coating tools, as both coatings have an extremely low friction coefficient and a low affinity for aluminium alloys. A comparison was made for DLC coated and uncoated tools in the end milling of A7075 aluminium alloy with a significant improvement being noted for the case of DLC coated tools [58]. Fortunately, the effect of material adhesion towards machining performance is not highly significant. Despite experiencing material adhesion in the turning of 6061 aluminium alloy, it was reported that the application of MQL managed to reduce tool wear [56]. This was confirmed by Tsao who investigated the milling of A6061PT651 aluminium alloy [59] where it was noted that the application of sulphurous boric acid ester cutting fluid in MQL conditions reduced the average flank wear by $12.5 \%$ compared to dry milling. Aware of the positive results in terms of tool wear, Lacalle et al. recommended the application of MQL for the high-speed milling of aluminium alloys [60].

Apart from tool wear reduction, the surface quality of the workpiece was found to be improved under MQL conditions. Diciuc and colleagues studied the effect of different lubrication methods (MQL, flood cooling and dry) on the surface roughness of a milled 7175 aluminium alloy workpiece [61]. Based on the experimental results, the lowest surface roughness value 
was achieved under MQL conditions in low $(118 \mathrm{~mm} / \mathrm{min}$ to $170 \mathrm{~mm} / \mathrm{min})$ and high (268 $\mathrm{mm} / \mathrm{min}$ to $375 \mathrm{~mm} / \mathrm{min}$ ) feed rates.

\subsection{Turning and milling of steel}

Various studies have shown the positive effects of MQL in the turning of steels. For example, Sohrabpoor and et al. used four different cooling conditions when turning AISI 4340 stainless steel workpieces: dry, air cooling, wet and MQL (where soluble oil was the cutting fluid used in wet and MQL conditions) [62]. Based on the results, the best performance was obtained under MQL conditions with respect to surface roughness and flank wear (Figure 6). The lower growth of flank wear in MQL turning can be explained by the heat reduction at the tool-chip interface as the mist produced in MQL has a higher interface penetration ability compared to wet cooling [62]. This result was confirmed by Dhar and colleagues who conducted a series of experiments with regards to the turning operations for both AISI 4340 and AISI 1040 steels [63]. It was reported that the heat reduction contributed to maintaining the sharpness of the cutting edge, thus providing a longer tool life, reduced tool wear, better surface finish and better tolerances. Furthermore, the chips produced from the turning of AISI 1040 steels under MQL conditions with a flowrate of $60 \mathrm{ml} / \mathrm{h}$ portrayed desirable properties such as being smoother, lighter in colour and with no trace of built-up edge (BUE) formation [63-65]. Ginting et al. concluded that, compared to traditional coolant, MQL can reduce the machining process cost of AISI 4340 steel since it requires less power and a shorter machining time [45].

Similar to turning, there was also a reduction in tool wear when milling steel workpieces. A machining test involving the milling of ASSAB HH718 steel reported reduced flank wear under MQL cooling conditions, especially at lower speed, feed and depth rates [66]. Overall, it was concluded that the performance shown was comparable to that from flood cooling with it being noted that the direction of the MQL nozzles is particularly important in the evaluation of tool wear as it is imperative that lubrication occurs between the chip and rake face [66]. With regards to surface quality in the milling of steels, it was concluded that cooling conditions did not affect burr height whereas the geometry of the milling cutter tool did [67]. 


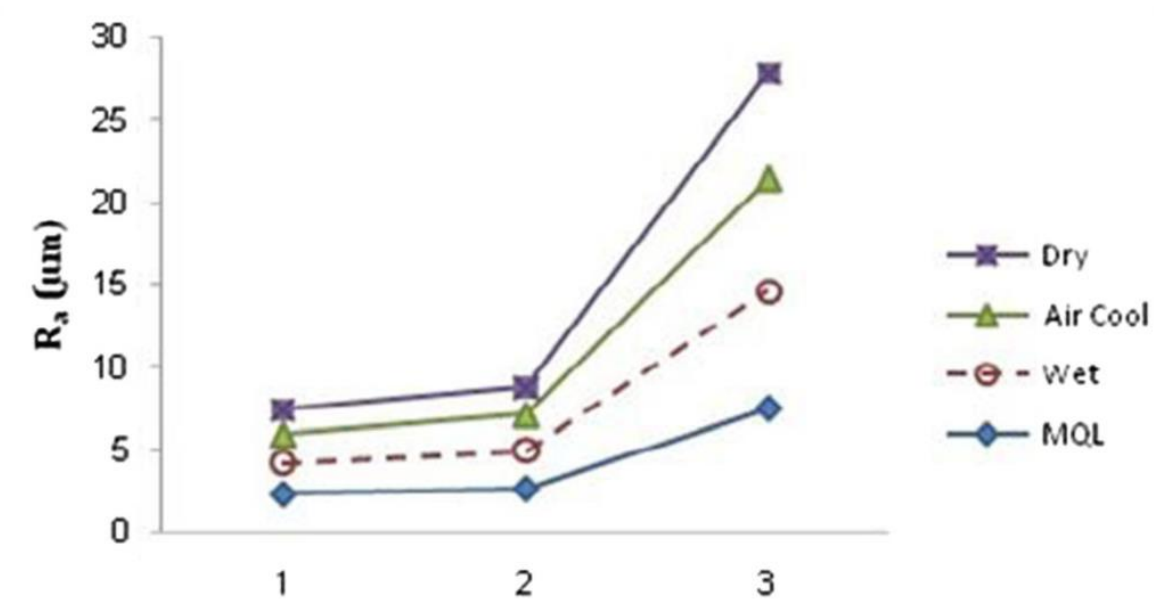

(a)

Condition

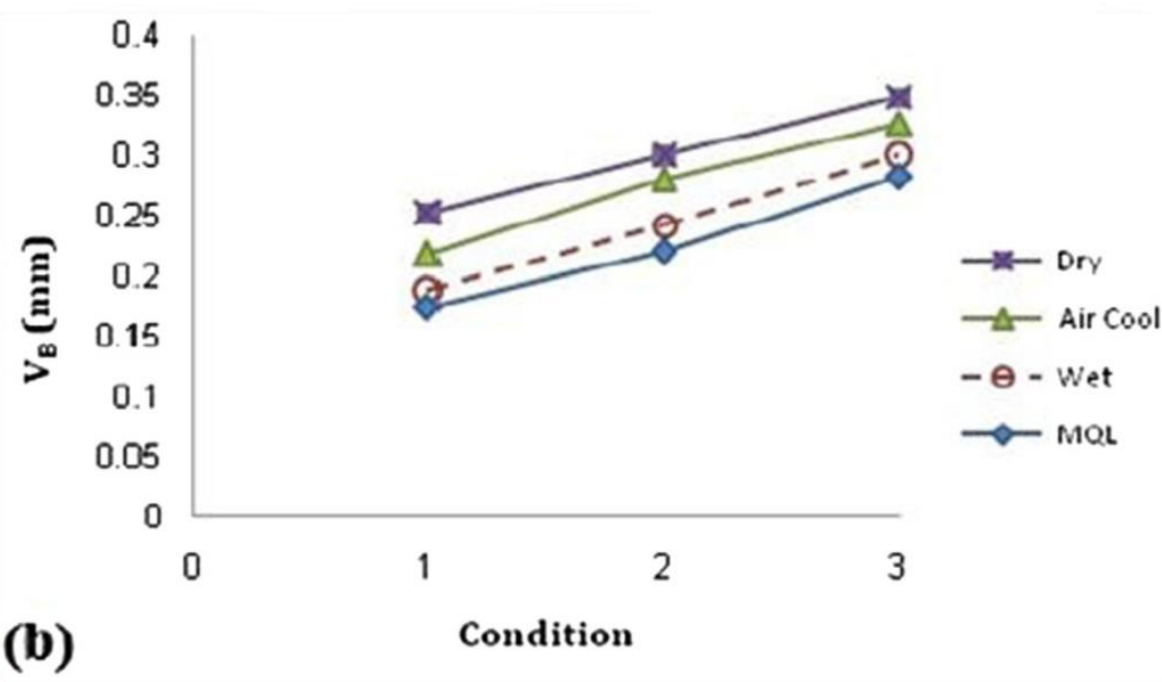

Figure 6: Effect of lubrication on machinability characteristics of AISI 4340 stainless steel turned parts: (a) surface roughness and (b) flank wear, with it being noted that MQL machining outperformed machining in dry, air cool and wet environments [62].

\subsection{Turning and milling of difficult-to-machine materials}

Studies on the turning of difficult-to-machine materials under MQL conditions have produced mixed results. The main debate sparked amongst the studies was based on the cooling and lubricating abilities of MQL. A study on the milling and turning of Ti-48Al-2Cr-2Nb intermetallic alloy under different cooling conditions (wet cooling, dry and MQL) was conducted [68]. The only significant improvement observed under MQL conditions was in respect to surface roughness (Figure 7) whereas wet machining was the ideal cooling condition in terms of tool wear/life (Figure 8) [68]. Difficult-to-machine materials are becoming 
increasingly popular due to their superior properties including exceptional strength and high corrosion resistance [69]. Some common examples of these materials are titanium alloys, nickel based alloys and iron based alloys [70, 71]. However, the metallurgical changes made to these materials have also reduced their machinability. The main challenge faced by manufacturers in the machining of difficult-to-machine materials is the generation of high temperatures. Harder materials usually produce a higher machining temperature when compared to softer materials as they possess a higher specific cutting energy, higher friction and deformation [72].

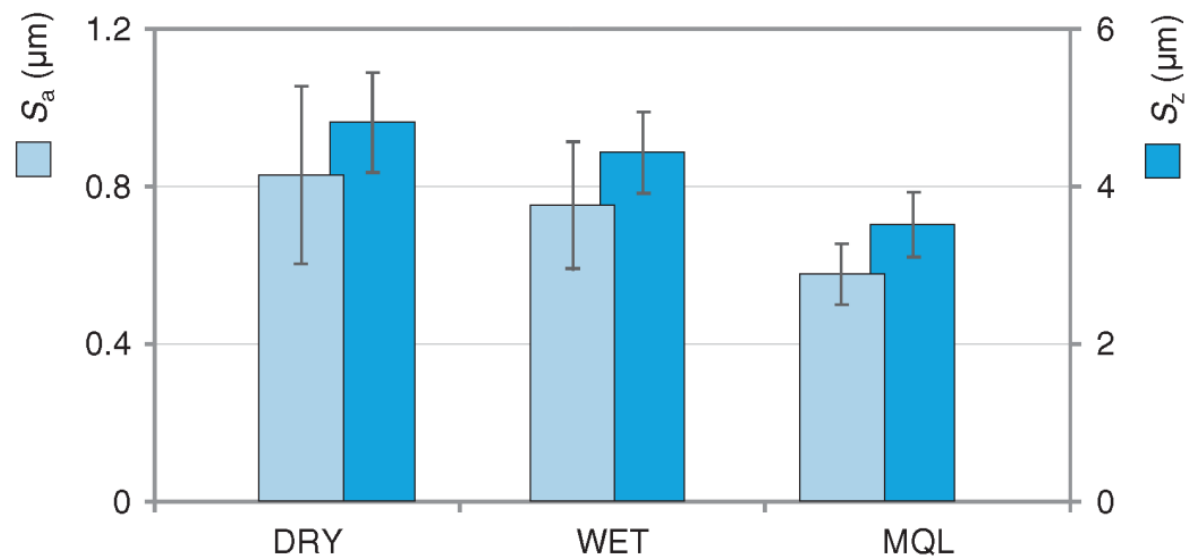

Figure 7: Surface roughness of turned parts under different cooling conditions [68].

Park et al. showed that MQL experienced intermediate flank wear compared with both dry and wet machining with its pattern being similar to that of dry machining [73]. Such a result can be explained by the significantly better cooling capability of wet machining compared to both dry and MQL conditions. However, Wang et al. argued that MQL has a similar cooling and lubrication ability as for flood cooling [74]. They studied the effect of different cooling conditions: wet, dry and MQL in the continuous turning and interruptive turning of Ti-6Al-4V titanium alloy. MQL exhibited the best overall performance in both continuous and interruptive turning, especially for two slot interrupted cutting and continuous cutting at a higher feed rate and cutting speed. It was suggested that these positive results were obtained due to the better lubrication ability of MQL compared to flood cooling [74]. However, Boswell and Islam found that, compared to MQL, cold water produces a better surface finish whilst cryogenic cooling improved tool life on a turning test of titanium alloy [75]. 


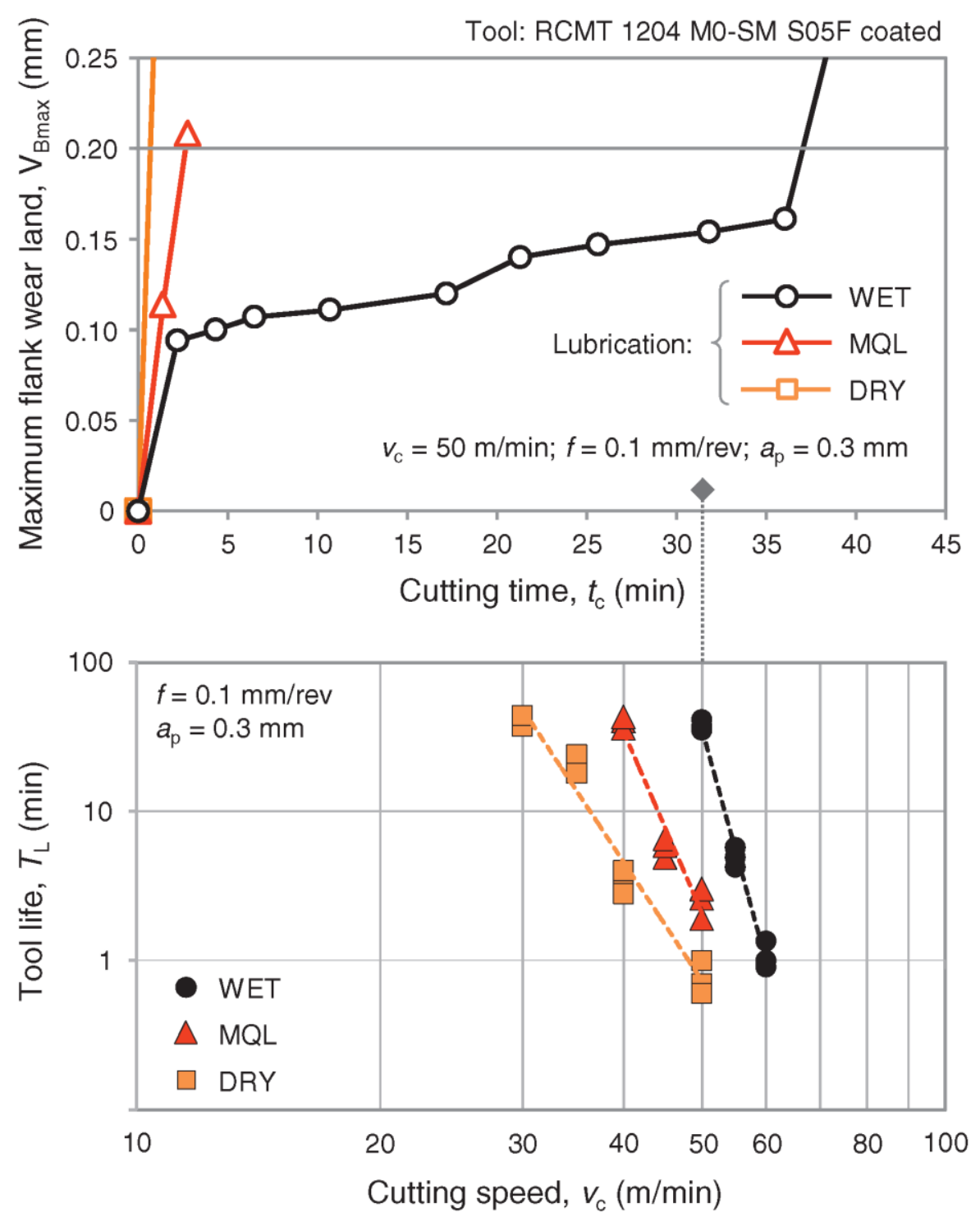

Figure 8: Effect of lubrication conditions on tool wear and tool life for turning [68].

In addition to titanium alloys, nickel based alloys have also been investigated under MQL conditions. A nickel copper alloy (MONEL alloy K-500) was studied under different cooling conditions [76]. From comparison of dry and MQL conditions, it was concluded that MQL was a better cooling condition as it had the ability to lower the surface roughness and cutting force by $38 \%$ and $59 \%$, respectively [77]. It was further explained that the improvement in surface roughness or surface quality is a result of lower cutting temperature [78]. In comparison to the suggestion of Wang et al. [74], MQL exhibited a cooling effect only in the turning experiment of Waspaloy conducted by Beno et al. [79] as evidenced by the absence of a significant 
reduction in the aspect of cutting force, which could only be explained by the lack of lubrication.

Park et al. investigated the face milling of Ti-6Al-4V titanium alloy using a series of ecofriendly machining technologies including MQL, cryogenic machining with liquid nitrogen, combination of cryogenic and MQL, as well as laser assisted machining (LAM) [73]. Results from these green techniques were then compared to dry and flood cooling. The main outcome of the experiment was a comparison of the electric power consumption by all machining methods (Figure 9). The electric power consumption was found to be maximum under wet machining conditions $(2.75 \mathrm{~kW})$ and followed by LAM, cryogenic, dry and MQL with the power consumption of MQL being only $1.53 \mathrm{~kW}$. The high power consumption of wet machining can be explained by the application of a pump for delivering and recycling cutting fluids. As for MQL, it is suggested that the minimal tool wear observed was the key factor leading to the lowest power consumption [73].

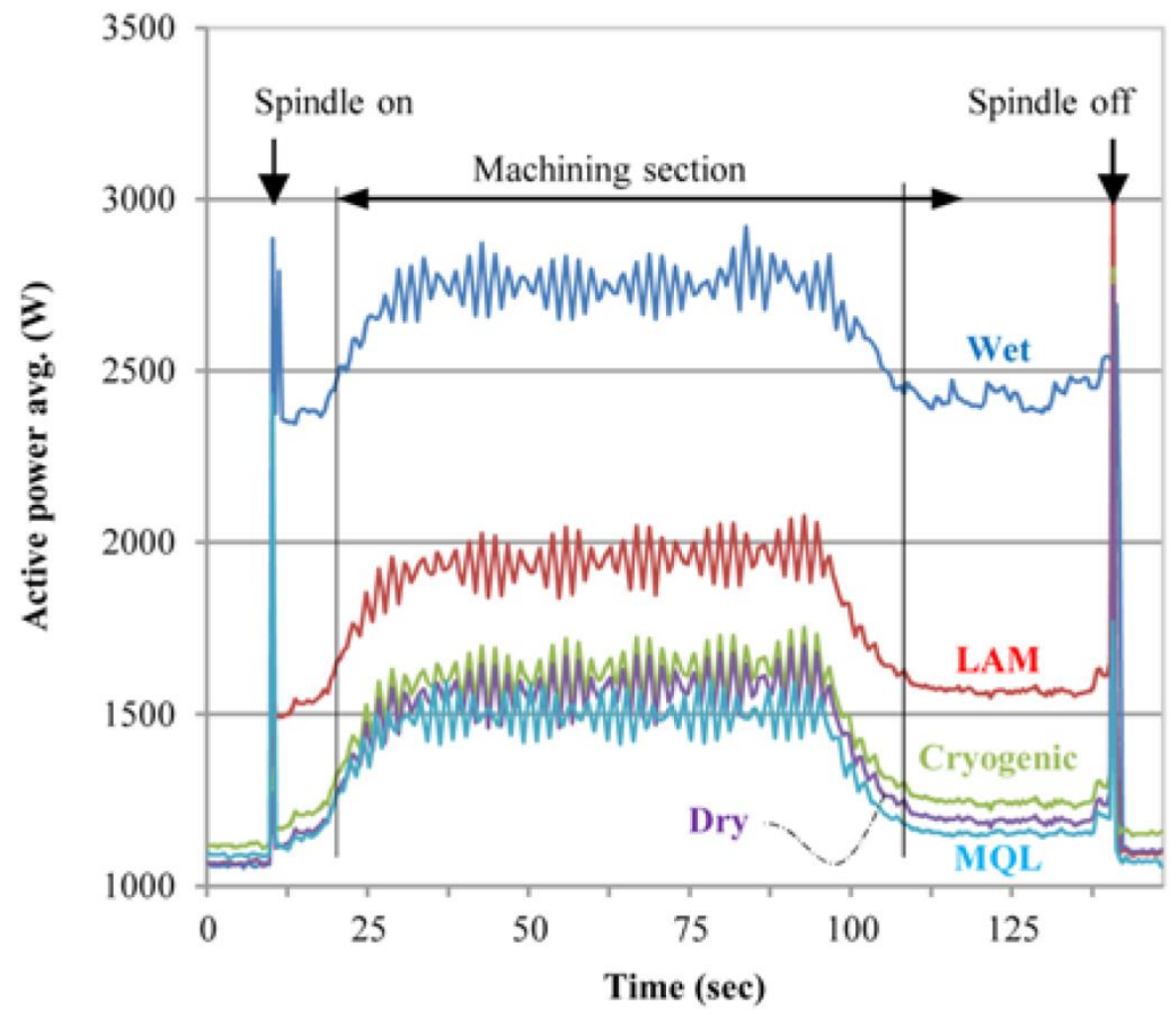

Figure 9: Influence of cooling method on electric power consumption at a cutting speed of $76.4 \mathrm{~m} / \mathrm{min}[73]$. 
Thamizhmanii and Hasan conducted an experiment on the milling of Inconel 718 with the conditions being vegetable based MQL and dry milling with the cutting tool being super hard cobalt [80]. It was reported that the cutting tool travelled longer under the condition of MQL with a flowrate of $37.5 \mathrm{ml} / \mathrm{hr}$ providing the optimum surface roughness and flank wear of the material. Moreover, the reduction in flank wear led to a tool life increase of $43.75 \%$ compared to dry milling [80].

\subsection{Drilling of aluminium}

Coated drills have also receiving great attention in the drilling of aluminium alloy. For example, Bhowmick and Alpas investigated the effect of a low-friction coating drill such as diamond-like carbon (DLC) under $\mathrm{H}_{2} \mathrm{O} / \mathrm{MQL}$ conditions at a rate of $30 \mathrm{ml} / \mathrm{h}$ with positive results [81]. Another example was that of Fox et al. who studied the influence of different coatings under MQL conditions on the drilling of aluminium silicon B319 cast alloy with diamond-coated and low hydrogen DLC drills exhibiting the best performance in the drilling of 50 holes with the latter being the best whilst drilling 500 holes [82]. In an attempt to reach 7000 holes, tool failure was experienced by the diamond-coated drill after 4300 holes whereas the low hydrogen DLC coated drill succeeded with minimum tool wear. However, several studies have also shown positive results without the use of coated drills. Davim and colleagues [83] investigated the effect of different cooling conditions on the drilling of AA1050 aluminium with the cutting tools and lubricants being uncoated K10 carbide drills and emulsion oil, respectively, under MQL conditions. Comparing the results with those recorded under flood cooling, it was reported that the performances were comparable. This was confirmed by additional experiments conducted by Braga and colleagues [84] who compared an uncoated K10 carbide drill and diamond coated carbide drill under both MQL and flood cooling conditions. Mineral oil was used in the application of MQL whereas soluble oil was supplied in the latter. It was shown that the diamond coated drill did not present any advantages when compared to the uncoated carbide drill and that both were subjected to similar amounts of flank wear. In fact, a higher feed force value was observed during the use of the diamond coated drill due to the presence of adhered chips on the tool nose. 


\subsection{Drilling of steel}

Similar to the MQL drilling of aluminium alloys, the drilling of steels using MQL has been found to yield positive results. For example, the drilling of AISI 1040 steel with high speed steel (HSS) drills under MQL conditions was found to improve the accuracy with an average temperature reduction of $10 \%$ at the tool chip interface in addition to providing the best hole surface texture [85]. Zeilmann et al. conducted drilling tests on AISI P20 steel using carbide drills with different drilling conditions being applied during machining, namely dry, emulsion and MQL [86]. Continuous drilling was adopted for the emulsion case whereas a pecking cycle was used for both dry and MQL conditions with an advance of $1.5 \mathrm{~mm}$ followed by a retreat out of the hole. The adoption of a pecking cycle was undertaken to avoid microchipping and facilitate chip evacuation. Figure 10 shows the plastic deformation experienced by the workpiece during drilling with the plastic deformation experienced under dry conditions being larger near the beginning and bottom of the hole. The emulsion technique and MQL were found to be comparable near the beginning of the hole but the plastic deformation experienced under emulsion cooling was larger at the end of the experiment. This difference can be explained in terms of the penetration of cutting fluid. At the beginning, the cutting fluid had no problem penetrating the cutting zone under emulsion conditions but this became increasingly difficult as the experiment progressed. Positive results were also observed in a deep hole drilling experiment with the tool life being improved in the machining of plain carbon steel using waterbased lubricant [87].

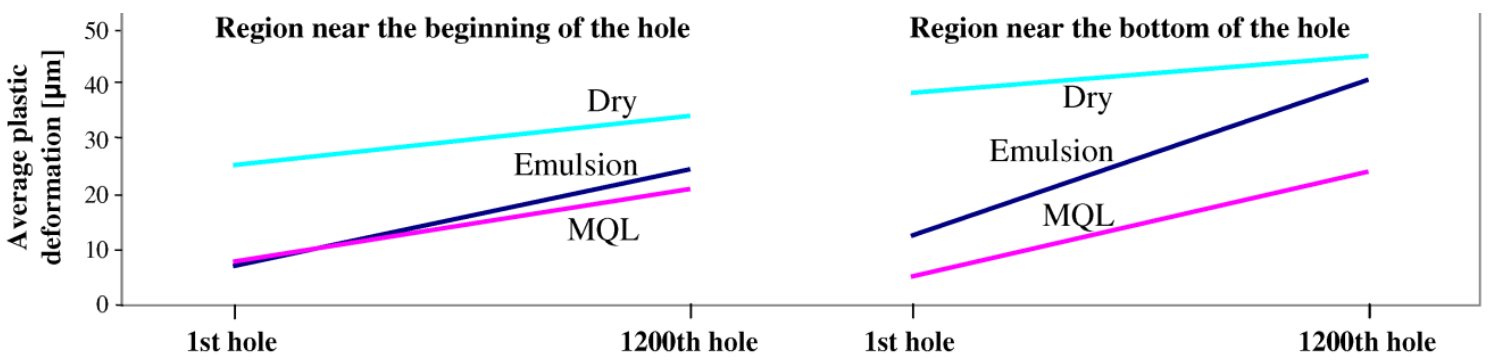

Figure 10: Average plastic deformation measured near the beginning and bottom of the holes [86]. 


\subsection{Drilling of difficult-to-machine materials}

A new group of automotive materials known as austempered ductile iron (ADI) is categorized as a difficult-to-machine material due to its impressive strength and hardness. A study on the drilling of ADI was conducted under dry, flood and MQL conditions by Meena and Mansori [88] with MQL being found to offer good machining performance in terms of average torque, average thrust force, average surface roughness and flank wear width, although not to the same extent as those obtained from conventional flood cooling (Figure 11). Rahim and Sasahara evaluated the effects of both synthetic esters and palm oil based MQL in the drilling of Ti-6Al$4 \mathrm{~V}$ titanium alloy and compared the results to those obtained from dry milling [42]. The main result of the research was the excellent improvement in terms of tool life with the improvement made from both synthetic esters and palm oil base MQL being as high as 306\% [42]. Another study on the drilling of Ti-6Al-4V aluminium alloy examined the drilling temperatures under different conditions [53] with internal emulsion exhibiting the smallest maximum temperature. In addition, the maximum temperature obtained from internal MQL was 50\% lower than that of externally applied MQL. This result was confirmed by Brinksmeier and Janssen who recommended the application of internal MQL for the machining of multi-layer composite materials comprising of carbon fiber reinforced plastic (CFRP), titanium and aluminium alloys [54]. 

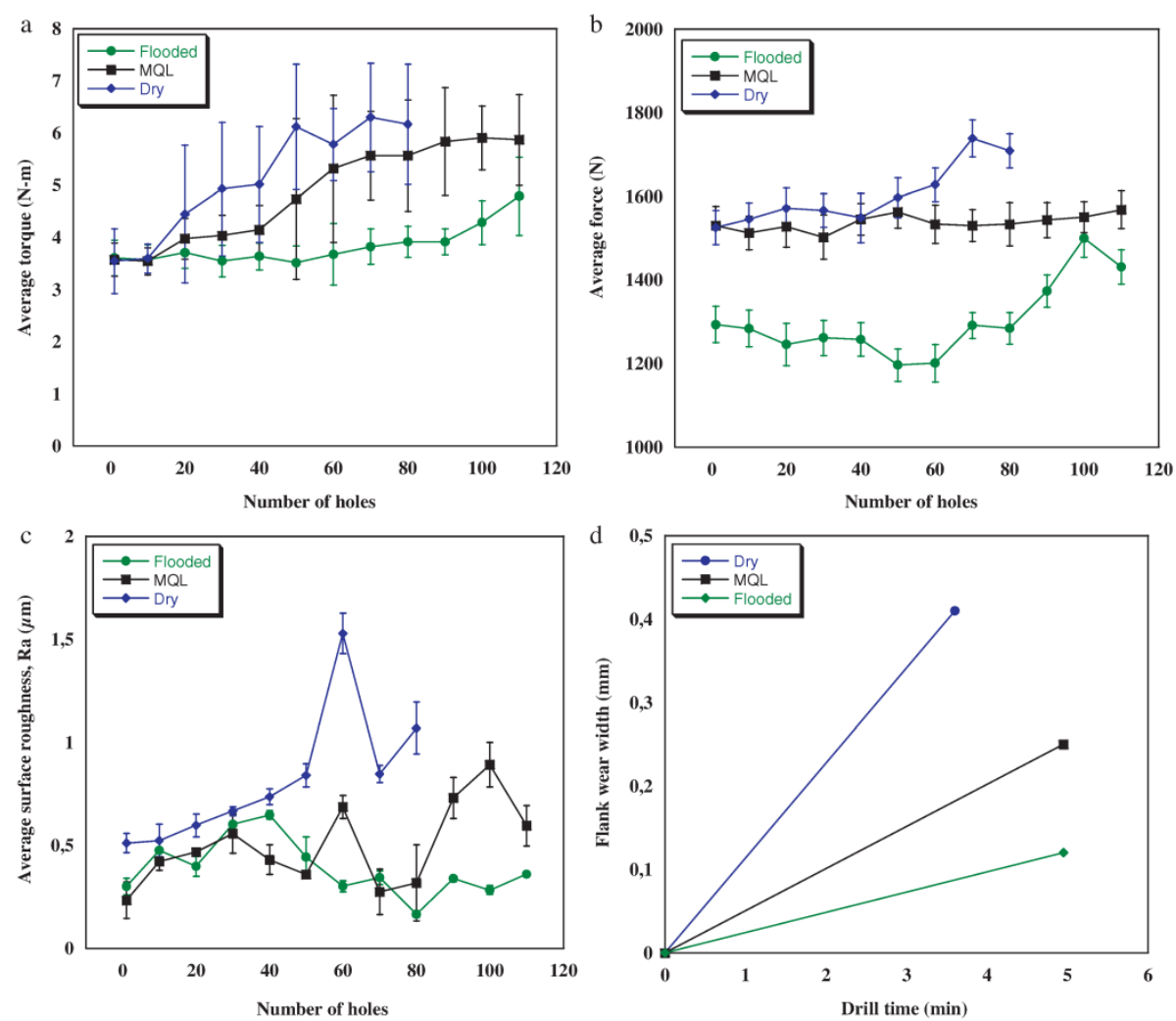

Figure 11: Effect of cooling conditions on (a) average torque, (b) average force, (c) average surface roughness and (d) flank wear width [88].

\subsection{Grinding of aluminium}

Due to the adhesive property of aluminium, grinding can be challenging as any chips generated tend to clog the grinding wheel [89]. Contrary to the good surface quality reported in milling experiments [61], the surface quality of AA6061 aluminium alloy in MQL grinding was found to be unsatisfactory with the surface roughness being between that of conventional flood cooling and dry grinding. Furthermore, under lower removal rates it was observed that the surface quality obtained from dry grinding surpassed that of MQL [37]. Aware of this issue, researchers have indicated that a silicon carbide ( $\mathrm{SiC}$ ) grinding wheel is ideal for aluminium alloys as the application of a SiC grinding wheel tends to lower forces and surface roughness $[37,90]$. This result is attributed to the easily fractured silicon carbide which provides new cutting edges with minimum tool wear (i.e., self-sharpening effect) during grinding [91]. Other than the type of grinding wheel, the optimisation of cutting parameters is essential in the grinding of aluminium alloys. A study on the effects of cutting parameters on the abrasive belt grinding of LY12 aluminium alloy was carried out with an increase in belt speed tending to 
decrease the surface roughness of the workpiece whereas an increase in workpiece travel speed or grinding depth led to a higher surface roughness [92].

\subsection{Grinding of steel}

A wide range of steels was investigated under grinding MQL conditions by Barczak et al. [8] and included common steels such as EN8, M2 and EN31, with a common alumina grinding wheel being used. It was reported that a comparable performance, if not better, can be achieved under MQL condition compared to flood cooling. However, MQL is not suitable for very hard materials [8] which can be explained by the high heat generated from grinding. A thermal analysis of MQL on the grinding process was made with it being observed that MQL provided good lubrication but was lacking in the cooling aspect compared to conventional flood cooling [93]. This result was confirmed by Yamin et al. in an experimental investigation of MQL grinding of AISI 1080 steel [94]. Mao et al. also noted the same trend based on the grinding of AISI 52100 hardened steel under dry, wet and MQL conditions with different cutting fluids, namely pure oil and a mixture of oil and water [95]. The workpiece temperature was measured under all conditions with the results being presented in Figure 12.

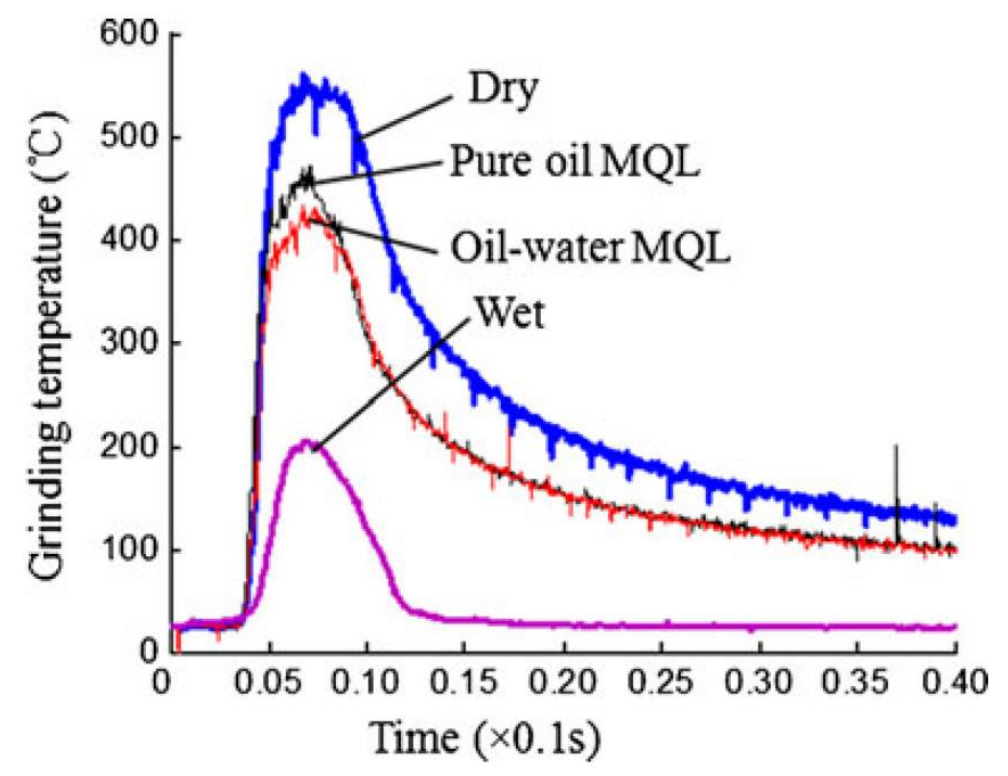

Figure 12: Influence of cooling condition on the grinding temperature of AISI 52100 hardened steel [95]. 
The peak temperatures for wet and dry grinding were found to be 192 and $561{ }^{\circ} \mathrm{C}$, respectively, with the peak temperature of MQL grinding being $90-130{ }^{\circ} \mathrm{C}$ lower than dry grinding. It is also apparent that there was no significant improvement with the application of oil-water cutting fluid in MQL compared to MQL using pure oil with only a small $\left(40{ }^{\circ} \mathrm{C}\right)$ decrease in peak temperature for the former compared to the latter [95]. This result indicates that, unlike drilling of aluminium alloys, the addition of water did not significantly improve the grinding of steel. Therefore, instead of focusing on the types of lubricant, Hadad et al. focused on the type of grinding wheel whilst investigating the temperature and energy partition for the MQL grinding of a hardened 100Cr6 steel workpiece under three cooling conditions: dry, wet and MQL [96]. A water-miscible fluid (5\% concentration) was selected for conventional wet cooling whereas an additional mineral oil and hydrocracked oil were used during the MQL tests with the MQL flowrate being in the range of $20-100 \mathrm{ml} / \mathrm{h}$ under an air pressure of 4-7 bar. Two types of grinding wheels were used, namely resin bond cubic boron nitride (CBN) and aluminium oxide, with the results showing that with the appropriate parameters, MQL grinding is not only applicable but in fact provides for a better performance compared to conventional flood cooling (Figure 13). Based on that experiment, the ideal parameters for the MQL grinding of hardened 100Cr6 steel are found to be: CBN wheel with mineral oil based MQL at an oil flowrate of 100 $\mathrm{ml} / \mathrm{h}$ and air pressure of 4 bar. The application of a CBN wheel also lowered the energy partition of the workpiece to a maximum of $31 \%$ under the same MQL conditions with this being explained in terms of the higher thermal capability of the CBN superabrasive [96].

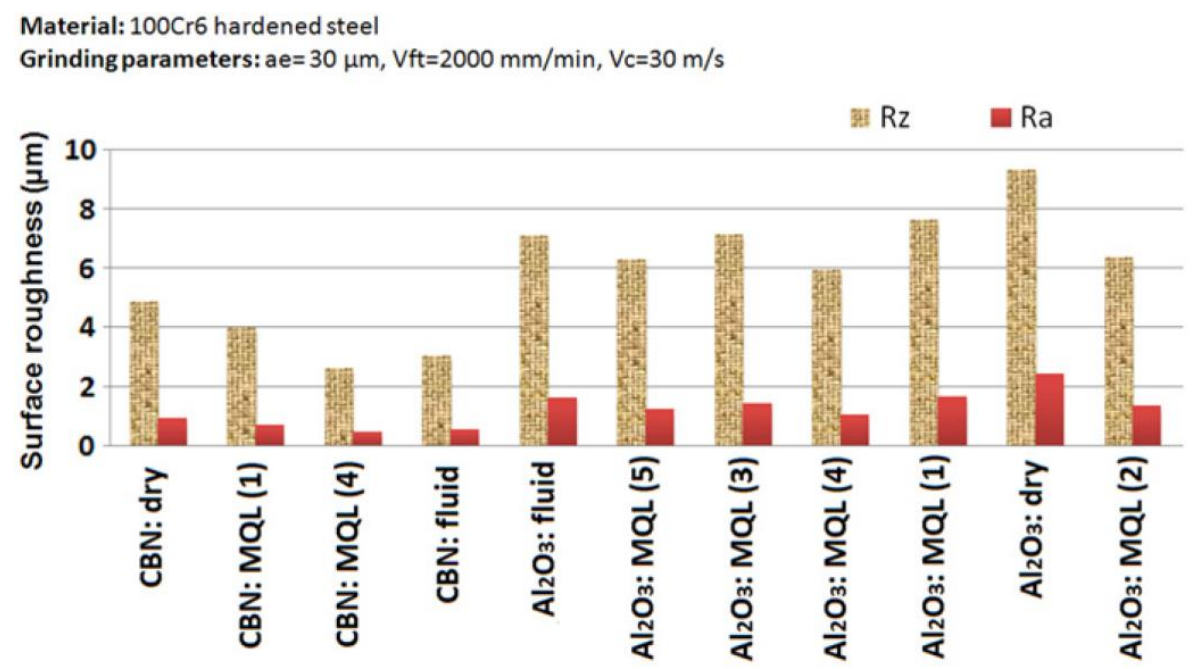

Figure 13: Influence of grinding parameters on the surface roughness of a 100Cr6 hardened steel [96]. 


\subsection{Grinding difficulties using MQL}

Concerning the grinding of challenging materials, Payne explained that it is of utmost importance that the coolant be delivered into the cutting zone [97]. Moreover, the optimisation of parameters such as type of abrasive, coolant, cutting speed and feed rate are essential in order to avoid damaging the workpiece [97]. There is very limited literature available for the grinding of difficult-to-machine materials, especially under the application of MQL conditions. However, Sadeghi et al. performed an extensive evaluation on the MQL grinding of Ti-6Al$4 \mathrm{~V}$ titanium alloy [48]. An extensive range of variables were applied including work speed, depth of cut and cooling conditions whilst additional parameters that were evaluated under MQL conditions have been shown in Table 1. It was observed that MQL grinding yielded a larger surface roughness compared to flood cooling (Figure 14) and that MQL with vegetable oil resulted in a particularly large surface roughness. However, a slight variation was recorded when synthetic oil was used as the MQL cutting fluid [48]. Due to its less than satisfactory performance, researchers have been focusing on advanced techniques such as using nanoparticles as additives for MQL cutting fluids [98] and cryogenic pneumatic mist jet cooling (CPMJ) [99]. Setti et al. performed an experiment using water based $\mathrm{Al}_{2} \mathrm{O}_{3}$ fluid under $\mathrm{MQL}$ conditions for the grinding of Ti-6Al-4V titanium alloy [98] with an MQL flowrate of $18 \mathrm{ml} / \mathrm{h}$ and pressure of 1.5 bar with two volume fractions of $\mathrm{Al}_{2} \mathrm{O}_{3}$ nanofluids (1.0\% and $4.0 \%$ ). The results showed that the grinding force (Figure 15) and surface roughness (Figure 16) were significantly enhanced under the application of a nanofluid compared with conventional MQL using coolant and water [98]. 
Table 1: Grinding conditions as used by Sadeghi et al. [48].

\begin{tabular}{|ll|}
\hline Grinding mode & Plunge surface grinding, down cut \\
\hline Grinding wheel & $\mathrm{Al}_{2} \mathrm{O}_{3}(91 \mathrm{~A} 46 \mathrm{I} 8 \mathrm{AV})$ \\
Grinding machine & FAVRETTO MB100 CNC surface grinder \\
Wheel speed $\left(V_{s}\right)$ & $V_{s}=15 \mathrm{~m} / \mathrm{s}$ \\
Work speed $\left(V_{w}\right)$ & $V_{s}=20,30,40 \mathrm{~m} / \mathrm{s}$ \\
Depth of cut (DOC) & $a=0.002,0.005,0.007 \mathrm{~mm}$ \\
Environments & Wet and MQL \\
Conventional wet grinding & Soluble oil (Blaser BC35) in a $5 \%$ concentration \\
fluid & $Q=20,40,50,60,70,100,140 \mathrm{ml} / \mathrm{h}$ \\
MQL flow rate & $P=3,4,5,6$ bar \\
Air pressure & Vegetable oil, synthetic oil, Behran cutting oil \\
MQL oil & 34, and Behran cutting oil 53 \\
Workpiece material & Ti-6Al-4V (50 mm x $20 \mathrm{~mm} \times 10 \mathrm{~mm})$ \\
Dresser & Six point diamond dresser \\
Dressing depth & Total depth of dressing $\left(a_{d}\right)=0.03 \mathrm{~mm}$ \\
Dressing speed & $V_{d}=5 \mathrm{~mm} / \mathrm{s}$ \\
\hline
\end{tabular}



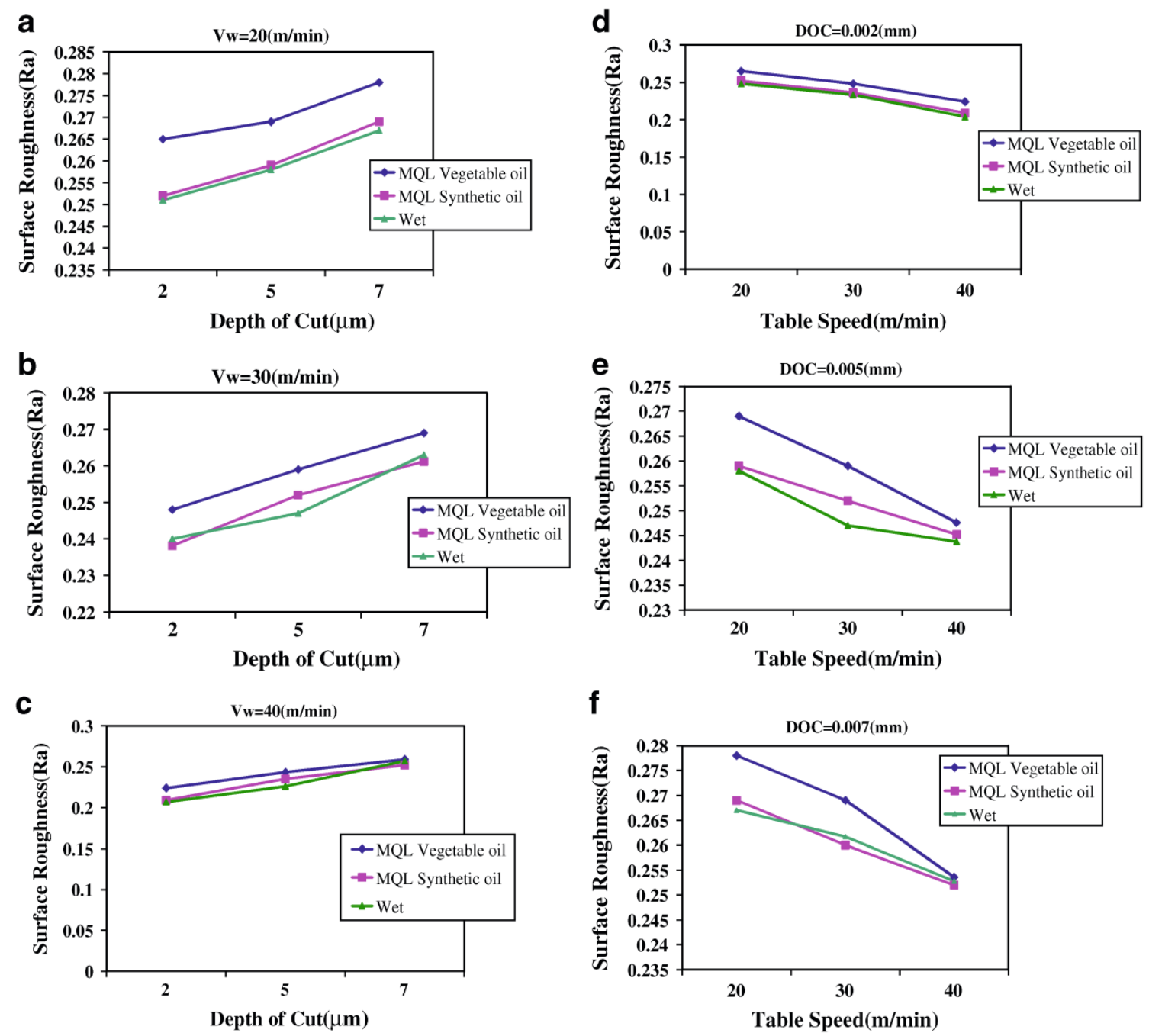

Figure 14: Effect of cooling condition on surface roughness for the grinding of Ti-6Al-4V titanium alloy [48]. 


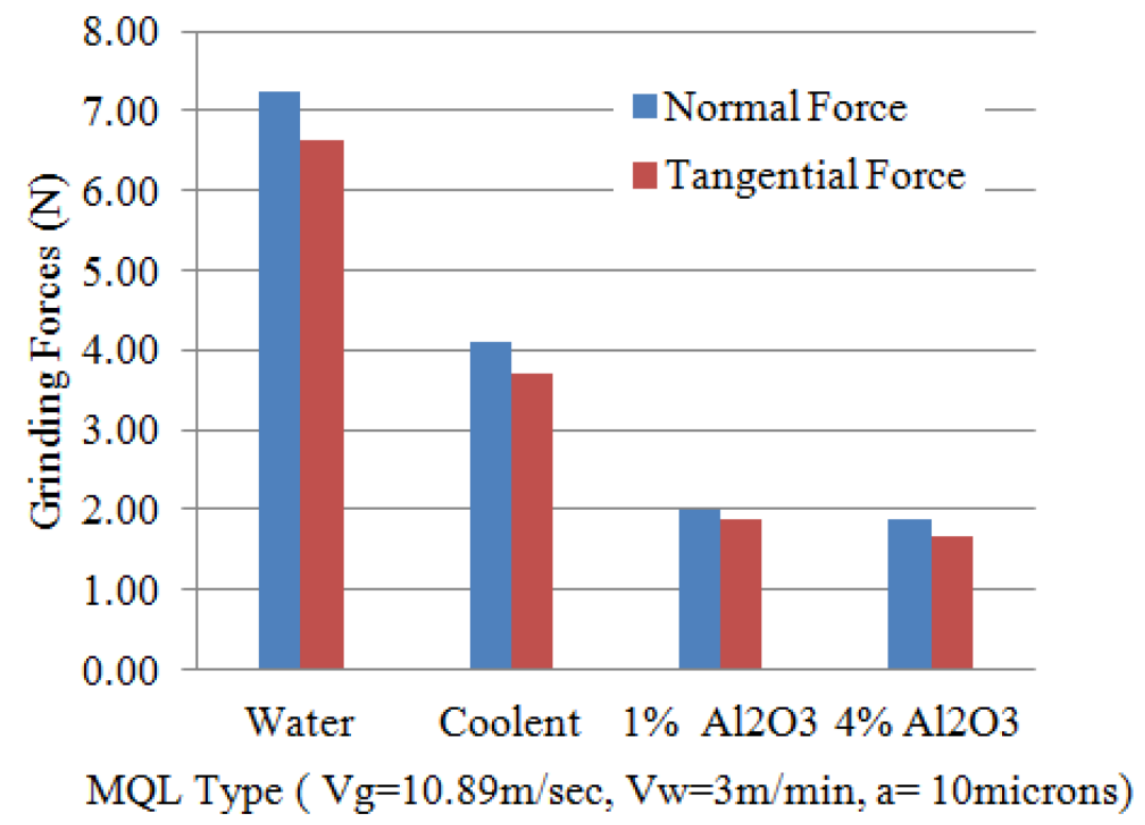

Figure 15: Effect of MQL cutting fluid on grinding force for a Ti-6Al-4V titanium alloy [98].

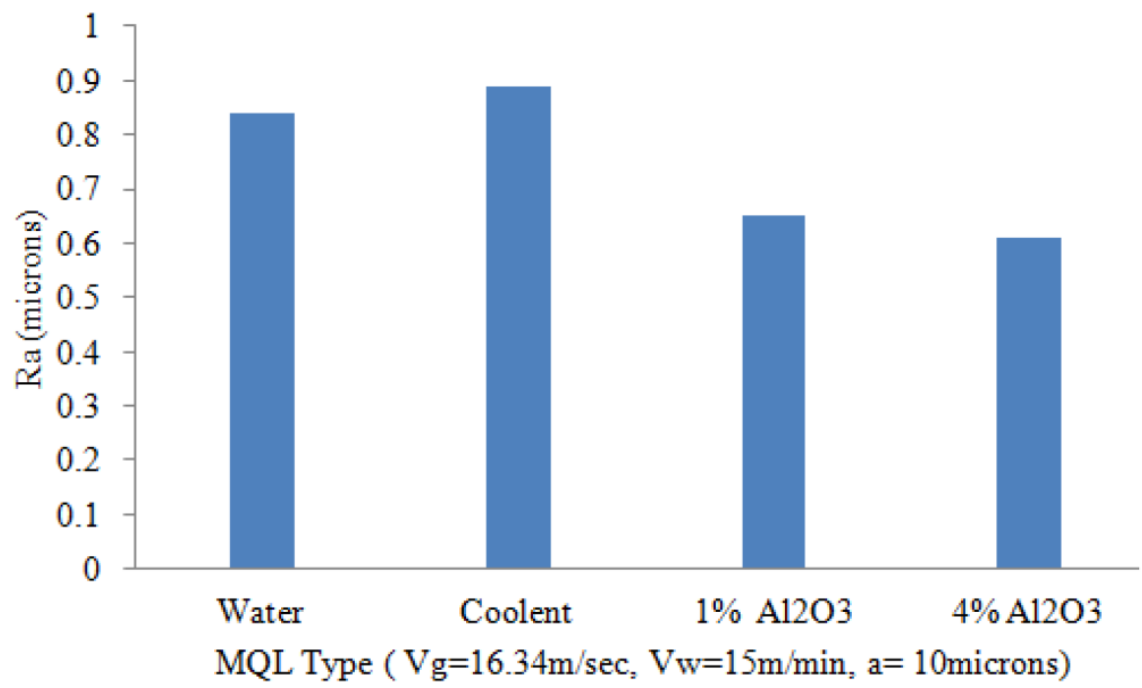

Figure 16: Effect of MQL cutting fluid on surface roughness for a Ti-6Al-4V titanium alloy [98].

\subsection{Summary of machining using MQL}

The general lack of adhesion problems during the machining of steels would suggest that MQL can result in improved performance compared to conventional cooling techniques. This trend was highlighted in the literature with MQL being concluded to be applicable in the four major 
machining operations: turning, milling, drilling and grinding, for steel workpiece materials. However, it is important to note the ideal parameters required in order to achieve satisfactory machining performance under MQL conditions, especially for drilling and grinding operations. For MQL drilling, a pecking cycle is advisable in order to avoid chip clogging and eventual tool failure. This can be explained by the ability of MQL droplets to reach the internal hole surfaces, providing both a lubrication and cooling effect. In the case of grinding, MQL consistently exhibited a significantly higher grinding temperature compared with conventional flood cooling which suggests that MQL lacks a significant cooling ability. To compensate for this shortfall, a superabrasive wheel with high thermal capacity has been recommended, e.g., resin bond $\mathrm{CBN}$ wheel. As for the MQL parameters, it was shown that mineral oil had better performance than either soluble oil or hydrocracked oil.

Unlike the case of steel, the main issue associated with the machining of aluminium and aluminium alloys is material adhesion. Based on the available research, it was shown that the amount of cutting fluid used in the machining of aluminium alloys significant influences the amount of material adhesion on the cutting tool. Therefore, dry machining is not advisable for aluminium and its alloys as dry machining involves zero cutting fluid. On the other hand, positive results were obtained in the milling and turning of aluminium alloys with MQL despite the adhesion issue, especially in the aspects of tool wear and surface roughness. As for drilling processes, although it was shown that the DLC coated drill is compatible for the drilling of aluminium alloys under MQL condition, uncoated K10 carbide drills would suffice by pairing it with appropriate lubricants, i.e., low viscosity lubricants. In the case of MQL grinding, limited literature is available and further research is therefore recommended, particularly on the selection of grinding wheels and cutting parameters in order to enhance the performance of MQL with aluminium and aluminium alloy workpieces.

The machining of difficult-to-machine materials is more complex mainly due to their higher hardness and this is recognized within the literature. Despite having a considerable number of studies performed for the MQL turning of difficult-to-machine materials, researchers were not able to arrive at a consensus with regards to the cooling and lubricating properties of MQL systems. Nevertheless, some improvements were observed with MQL, especially in the milling of difficult-to-machine materials, with the main improvements being with regards to tool wear and tool life. For drilling and grinding experiments, MQL showed intermediate results with 
several studies indicating that MQL was usually better than dry machining but that conventional flood cooling ultimately outperformed MQL.

In general, MQL is an effective technique for machining. However, the extent of its effectiveness is dependent on various factors including workpiece material, type of machining operation, machining and other parameters associated with MQL such as flowrate, compressed air pressure, type of lubricant and delivery method. However, in spite of this, there were two consistent conclusions obtained from the application of MQL:

(1) Tool wear improvement: compared to conventional flood cooling, tool wear improvement $[59,100]$ was consistent in most studies taking into account the differences in materials and machining types.

(2) MQL is better than dry machining: other than the machining of low hardness steels, MQL outperforms dry machining in the above mentioned materials. This can be explained by the application of cutting fluids, since lubrication and cooling are the main functions of cutting fluids. Therefore the absence of cutting fluids in dry machining is not ideal.

Based on the reviewed literature, there is still a debate concerning the cooling and lubrication capabilities of MQL. Some researchers have suggested that MQL lacks a cooling effect [9395] while others have suggested the opposite point of view [74, 77]. These inconclusive results act as a key motivator to the advancement of MQL which will be discussed in the next section.

\subsection{Advancements in MQL}

Although MQL is proven to be a good alternative for traditional flood cooling, its cooling and lubricating effects are still in question. Therefore, researchers have been exploring ways to enhance the effectiveness of MQL by improving both its cooling and lubricating effects as shown in Figure 17. 


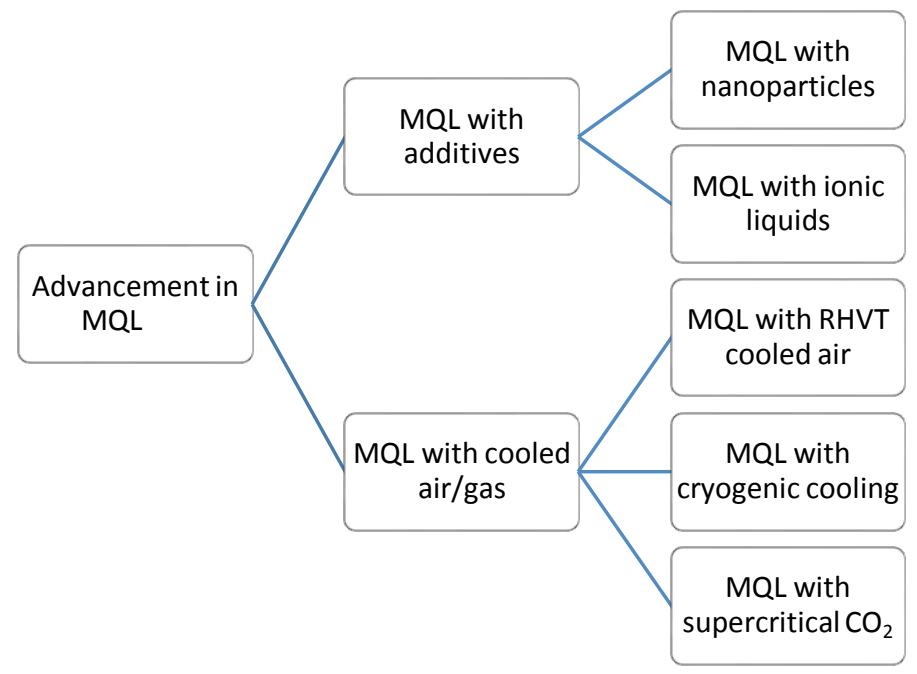

Figure 17: Advancements in MQL.

\subsection{MQL with additives}

Since MQL involves only a small amount of lubricant, it is essential to make sure that the lubrication provided is sufficient. Lubrication is important as it can affect the life of a cutting tool as well as the surface quality and tolerance of the machined workpiece [101]. Therefore, researchers have investigated the addition of nanofluid $[20,102,103]$ and ionic liquid [104$106]$ in order to study their effect and performance.

\subsection{MQL with nanolubricants}

Nanolubricants or nanofluids are defined as suspensions of nanoparticles in a base fluid and they can be designed or engineered based on the desired properties. The four design parameters are nanoparticles, base fluid, additives and scale [107]. The addition of these nano-sized particles not only permits penetration to the cutting interface but also increases the heat transfer capability as the nano-sized solids generally have a much higher thermal conductivity compared to liquids $[107,108]$ as shown in Table 2. 
Table 2: Thermal conductivity of typical solids and liquids used in MQL with nanolubricants [107].

\begin{tabular}{|c|c|}
\hline Material & Thermal Conductivity $(\mathbf{W} / \mathbf{m K})$ \\
\hline Carbon nanotubes & 3000 \\
\hline Aluminium oxide & 40 \\
\hline Water & 0.60 \\
\hline Vegetable oils & 0.18 \\
\hline
\end{tabular}

The thermal behaviour of nanofluids containing various nanoparticles has been widely researched including $\mathrm{Al}_{2} \mathrm{O}_{3}$ [109], $\mathrm{TiO}_{2}$ [110, 111], $\mathrm{SiC}$ [112] and $\mathrm{NiFe}_{2} \mathrm{O}_{4}$ [113]. Overall, it has been observed that the thermal conductivity of the MQL increases as the concentration of nanoparticles increases, although the linearity of the relationship is still in question [114].

Another advantage offered by nanofluids is the lubrication mechanism of nanoparticles. Nanofluids have higher lubricity as the nanoparticles provide for several beneficial mechanisms including the formation of a surface protective film, rolling effect, polishing effect and mending effect, whereupon the nano-sized particles can be deposited on the "damaged" surface in order to compensate for the loss of mass [115-117].

Aware of the multiple benefits offered by nanofluids, considerable research has been carried out to better understand the effectiveness of nanoparticles as an additive to lubricants for contact lubrication applications [118-120]. As an extension to that, the effects of nanofluids in MQL applications has recently been investigated and has yielded positive results. A summary of the effects of various nanoparticles in machining is presented here:

- $\mathrm{MoS}_{2}$-paraffin oil/soybean oil [102]: Better performance was shown with higher concentrations of nanoparticles. A minimum friction coefficient of 0.22 and a reduction of $53 \%$ in energy consumption were observed with these nanolubricants whilst wheel life was enhanced. 
- $\mathrm{MoS}_{2}$-paraffin oil/soybean oil [103]: A reduction of 45-50\% in the force-ratio and 48$55 \%$ in abrasive wheel wear was observed with these nanolubricants.

- Graphite-LB2000 vegetable-based oil/PriEco6000 unsaturated polyol ester [121]: Graphite oil-based nanofluid MQL led to a reduction in cutting force and temperature compared to dry cutting and conventional MQL in turning. Increasing the mass fraction of nanographite caused a reduction in the cutting force and temperature, irrespective of the base oil type. However, with the same mass fraction of graphite nanoparticles, LB2000 exhibited a lower cutting force and temperature especially at high cutting speeds.

- $\mathrm{Al}_{2} \mathrm{O}_{3}$-pure water [20]: Addition of nanoparticles led to a reduction in the tangential grinding force and grinding force ratio. The peak temperature within the cutting zone of nanofluid MQL grinding was approximately $40^{\circ} \mathrm{C}$ lower than for normal MQL grinding.

- $\mathrm{MoS}_{2}$-paraffin oil/soybean oil [108]: MQL with nanoparticles showed an energy ratio coefficient and specific grinding energy of 41.4 and 35\% which was lower compared to conventional MQL (52.1 and $45.5 \%$, respectively).

- $\mathrm{Z}_{\mathrm{r}} \mathrm{O}_{2}$-oil [108]: The presence of these nanoparticles ensured satisfactory cooling performance while the presence of $\mathrm{MoS}_{2}$ showed satisfactory lubrication performance. The cooling effects of 2 vol\% nanoparticles was considered ideal.

- $\mathrm{MoS}_{2}$-ECOCUT HSG 905S [122]: The quality of the machined surface was improved when $0.5 \mathrm{wt} \%$ of nanoparticles was added to the MQL as opposed to either pure oil or any other nanoparticle concentration.

- $\mathrm{MoS}_{2}$-Eraoil KT/2000 commercial vegetable oil [21]: The minimum initial tool wear and surface roughness were obtained using nanofluid MQL at a $40 \mathrm{ml} / \mathrm{h}$ flow rate as compared to conventional MQL and dry cutting.

It is apparent from the above research that the addition of nanoparticles to MQL fluid has proven successful. Significant improvements can be seen in various parameters including energy consumption [102, 108], cutting and grinding forces [20, 103, 108], temperature [121], tool wear [21] and surface quality of the workpiece [21, 122]. Recently, a hybrid of $\mathrm{MoS}_{2}$ and CNT nanoparticles was investigated by Zhang et al. in the MQL grinding of Ni-based alloy [123] with it being reported that a $6 \%$ mass fraction of $\mathrm{MoS}_{2} / \mathrm{CNT}$ nanoparticles with a ratio of 2:1 offered better lubrication compared with pure nanoparticles. However, this approach is relatively new and in order to obtain maximum efficiency in machining processes, research on 
the compatibility between base fluid and nanoparticles, nanofluid and workpiece material, in addition to the lubrication system set up, still need to be investigated.

Despite providing positive effects in machining, there are concerns expressed by manufacturers towards the use of nanofluids. Although one of these is economic in aspect, fortunately the price of nanofluid is similar to that of the base fluid. For example, the cost of nanolubricant containing $0.5 \mathrm{wt} \% \mathrm{MoS}_{2}$ concentration is only $2.5 \%$ higher compared to the standard lubricant which is a good trade off when taking into account the improved performance [122]. Perhaps a more important concern is the toxicology of nanoparticles. Ironically, the advantageous size of nanoparticles in machining operations is an issue affecting human health as these particles can be easily transferred to the human body through inhalation or transdermally. Once inside the human body, the nanoparticles will translocate to other tissues and organs, resulting in damage [124-127]. As there are countless variables involved in the engineering of nanoparticles, there is no regulatory framework yet available to accommodate this issue. Nevertheless, it is advised to use the smallest feasible concentration of nanoparticles in order to minimise any toxicity [128].

\subsection{MQL with ionic liquid}

Studies have also been made on ionic liquid (IL), which is an organic salt with low melting point $\left(<100^{\circ} \mathrm{C}\right)$, as an additive for MQL applications [104, 129]. With its excellent lubrication properties, ionic liquids have had extensive research in the area of sliding/rolling between different material pairs, for example, steel to steel [130, 131], steel to aluminium [132-134] and titanium to steel $[135,136]$. In addition, the low volatility of ionic liquids has encouraged researchers to extend their study into MQL applications as a step towards green machining [137]. However, the application of IL-based MQL is relatively new and there is limited literature available. Davis et al. recently reported a $60 \%$ and $15 \%$ reduction in tool wear in the machining of titanium when compared with dry machining and conventional flood cooling, respectively [104]. A milling experiment on AISI 1045 carbon steel has also been conducted with it being reported that the surface roughness of the workpiece under the application of ILbased MQL was comparable with that of flood cooling whereas MQL without the addition of IL yielded higher surface roughness [105]. Positive results on surface roughness have also been noted in the micromachining of Al 5052 aluminium alloy [106]. 
The biggest similarity in the aforementioned experiments is the amount of IL involved with between 0.5 and $1 \mathrm{wt} \%$ of IL typically being added into the base oil for MQL applications. This is a significant point as it shows that even a small amount of IL is sufficient to affect the cutting performance in machining processes, thus highlighting that IL has the potential to improve the effectiveness of MQL. However, similar to the case of nanoparticles, the two main concerns associated with IL are economic and ecological in nature. It has been pointed out that the price of IL is relatively high with a typical range of $€ 23$ to $€ 100 \mathrm{~kg}^{-1}$ [138]. With respect to ecology, it is proving challenging for researchers to study its toxicology as the ionic liquid can be significantly engineered based on the desired properties [139]. Some reports have stated that the toxicity found in IL was comparable or even greater than that of common solvents such as methanol, acetone and ethanol [140-142]. However, such a view is not unanimous between researchers [143] and it is believed that the contradictory results can be attributed to an inadequate testing methodology.

\subsection{MQL with cooled air/gas}

As mentioned earlier, it has been demonstrated that the cooling properties of MQL are not sufficient $[144,145]$ with this being attributed to the common medium used in transporting lubricant droplets, namely, room temperature compressed air. To counter this issue, researchers have started to combine cooled air/gas and MQL with promising results [146, 147].

\subsubsection{MQL combined with a Ranque-Hilsch vortex tube}

The Ranque-Hilsch vortex tube (RHVT) is widely used in various operations including thermal tests, dehumidification, gas liquefaction, ice production and mixture separation whilst also providing cooling and heating applications in machining processes [22, 148]. RHVT comprises of one or more inlet nozzles, allowing the flow of compressed air. The separation of gas takes place in the tube whereupon two streams with different temperatures (hot and cold) will be divided towards different exits [149]. One of the big advantages of RHVT is that it does not involve any moving parts and its functionality requires no chemicals or electricity, thus requiring little in the way of maintenance $[22,148]$.

Researchers have evaluated several aspects associated with RHVT including its cooling performance [150] as well as influential parameters such as length to diameter ratio [151, 152] 
and types of air [153]. Based on the available literature, significant improvements have been observed in a comparison between the cutting tool temperature with and without the application of RHVT. For example, it was found that the maximum performance of RHVT resulted in a temperature difference of $97^{\circ} \mathrm{C}$ [150] with this decrease in temperature also leading to the minimization of BUE and thus providing a better quality product for soft materials [154]. Furthermore, tool wear can be reduced by the application of RHVT cooling, especially for higher cutting speeds [155].

In accordance to the aforementioned benefits, researchers have proposed the combination of MQL and RHVT cooling with a suitable mixture of air and liquid. It is believed that, if successful, the combination of both techniques will provide a higher pressure with better lubrication, thus prolonging tool life $[22,156]$. This has led to promising results for the case of a finite element modelling (FEM) and computational fluid dynamics (CFD) study into the tool tip temperature. It was observed that the maximum interface temperature under the condition of combined MQL and RHVT cooled air was only $10 \%$ higher than that of wet machining which suggested the possibility of tool failure to be low [157]. In an experiment on end milling involving $\mathrm{MQL}$ and cooled $\left(-5^{\circ} \mathrm{C}\right)$ air, a comparable surface finish and low cutting force was observed as had been the case for conventional wet milling of aluminium alloy [147].

However, overall there is very limited research available concerning this technique. Therefore, future work incorporating different materials and machining processes is suggested in order to allow a more thorough evaluation on the effectiveness of combined MQL and RHVT cooling.

\subsection{Cryogenic MQL}

Cryogenic MQL (CMQL) is a combined lubrication system involving the techniques of cryogenic cooling and minimum quantity lubrication. Similar to the approach of combined MQL and RHVT cooling, the main theory behind this technique is to cool the workpiece. Upon reviewing the available literature for both combined MQL and RHVT and CMQL, it is obvious that the main difference between the aforementioned techniques is the method used in the transportation of cold air. As the name implies, RHVT is used in the method of MQL and RHVT [147, 157] whereas a refrigeration system is used in CMQL [158, 159].

Cryogenic cooling has been studied extensively in different machining processes including milling [160, 161], turning [162, 163], drilling [164] and grinding [165] with positive results. 
However, the combination of cryogenic cooling and MQL has only recently been explored. Based on studies made on the machining of titanium alloys, CMQL showed a significant reduction in temperature (cutting temperature and machined workpiece), cutting forces, surface roughness and tool wear $[51,166]$. These positive results are seen in other studies with Zhang et al. reporting a significant improvement in localised flank wear during the hard milling of $\mathrm{H}$ 13 steel [158] whilst a 124\% improvement in tool life for the machining of Inconel 718 under CMQL conditions has been noted when compared to dry machining [159]. Other than practical experiments, computer aided analysis has been performed to evaluate factors that may affect the performance of CMQL with the following parameters being suggested for optimum performance: lower temperature, higher flow of cold air, $8.5 \mathrm{~mm}$ inlet diameter and $3 \mathrm{~mm}$ outlet diameter (for nozzles) [167].

\subsection{MQL combined with carbon dioxide}

Another similar approach that has been studied involves the combination of $\mathrm{MQL}$ and $\mathrm{CO}_{2}$ at low temperature with the aim of creating a frozen layer of oil at the contact interface. In order to achieve an ideal frozen layer thickness, a $\mathrm{CO}_{2}$ flowrate of typically $40 \mathrm{l} / \mathrm{min}$ is applied at $238 \mathrm{~K}$ following the application of oil by MQL. It has been noted that this new approach can result in improved surface finish and lower wheel wear compared to conventional flood grinding in addition to requiring approximately half the energy compared to dry grinding [168, 169]. A similar approach involving supercritical $\mathrm{CO}_{2}$ and soybean oil was carried out in the rough turning of Inconel 750 with the main reason behind the use of supercritical $\mathrm{CO}_{2}$ being to counter the issue of limited heat dissipation offered by compressed air. Supercritical $\mathrm{CO}_{2}$ has excellent solubility for aliphatic and most aromatic hydrocarbons and thus can carry a wide range of metalworking lubricants in solution [145, 170]. The results obtained from the experiment were extremely promising with an increased tool life and material removal rate together with a reduced tool wear rate [146].

Despite yielding positive results, the use of $\mathrm{CO}_{2}$ for machining operations is controversial due to it being one of the primary greenhouse gases. It is apparent that the increased concentration of greenhouse gases may result in further rises in global temperature which is undesirable [171]. Whereas the use of alternative gases such as nitrogen has been suggested by some researchers [172], others have countered otherwise with Lozowski [173] stating that there will be no contribution to the greenhouse effect if the $\mathrm{CO}_{2}$ is initially withdrawn from the 
environment and then returned to the environment following its use. Such an argument was supported by a life cycle assessment that showed a lower overall environmental impact for supercritical $\mathrm{CO}_{2}$ compared with aqueous metalworking fluid [174]. Furthermore, reusing waste $\mathrm{CO}_{2}$ is encouraged in order to reach a net reduction of the respective global warming potential (GWP) [175].

\subsection{Summary of MQL developments}

To determine the effectiveness of various types of MQL development, four main parameters were looked at in terms of machining: tool wear, tool life, surface quality and cutting forces. Based on the trends shown in Table 3, MQL containing nanofluids (MQL $+\mathrm{NP}$ ) is the most promising method, whereas the other four methods have their own strengths and weaknesses. However, this result is not totally conclusive as there are exists significant gaps in the literature for MQL + IL, MQL + RHVT, CMQL as well as MQL + supercritical (SC) $\mathrm{CO}_{2}$. Therefore, this gap in the available research needs to be minimised by focusing on the aforementioned MQL techniques.

Table 3: Comparison between the different types of MQL developments.

\begin{tabular}{|c|c|c|c|c|c|}
\hline $\begin{array}{c}\text { Types of MQL } \\
\text { /Improvement }\end{array}$ & $\begin{array}{c}\text { MQL + } \\
\text { NP }\end{array}$ & MQL + IL & $\begin{array}{c}\text { MQL + } \\
\text { RHVT }\end{array}$ & CMQL & $\begin{array}{c}\text { MQL + SC } \\
\text { CO }_{2}\end{array}$ \\
\hline Tool wear & & & & & \\
\hline Tool life & & & & & \\
\hline Surface quality & & & & & \\
\hline Cutting forces & & & & & \\
\hline
\end{tabular}

\subsection{Conclusions}

A review of the effectiveness of minimum quantity lubrication in machining has been presented based on the existing literature. It is suggested that MQL provides good performance in machining mainly as a result of reducing the cutting zone temperature, resulting in decreased 
adhesion. Based on the available research, it is concluded that MQL is an effective sustainable cooling technique which is deemed feasible to replace conventional flood cooling. Due to the significant reduction in cutting fluid consumption compared to standard cooling techniques, the application of MQL has the ability to largely reduce the hazards caused by conventional flood cooling towards human health and the environment. Furthermore, the use of MQL also provides for financial incentives due to its low oil consumption and the availability of clean chips for selling.

In terms of machining effectiveness, MQL has shown great promise for the fundamental machining operations, namely turning, milling, drilling and grinding. Improvements resulting from the application of MQL were reported in various aspects including tool wear, surface roughness, cutting temperature and cutting forces for workpiece materials of aluminium and its alloys, a wide range of steels and even for difficult-to-machine materials. In addition, the authors reviewed recent developments made in MQL including the introduction of nanoparticles and ionic liquids into MQL cutting fluids, as well as hybrid MQLs by combining cooled air/gas such as RHVT cooled air, supercritical $\mathrm{CO}_{2}$ and refrigerated air with MQL. Based on the available literature, the aforementioned developments were shown to be successful in terms of increasing the lubricity and cooling effect of a MQL system. As the lack of a significant cooling effect was found to be the main disadvantage of standard MQL during machining, it is recommended that further research needs to be carried out on hybrid MQL systems such as MQL and RHVT.

It was apparent from the lack of reviews on nanoparticle toxicology that additional research concerning the toxicology of nanoparticles (and ionic liquids) is urgently required. Finally, there exists several research gaps that were identified by the authors and which are outlined in the future research section.

\subsection{Future research}

The authors have no doubt that MQL will have a promising future despite it not yet being widely adopted. Based on the available literature outlining the various advancements and improvements of MQL, the authors predict that industrial applications of nanofluid-based MQL and MQL + RHVT will increase dramatically in the near future. On that note, several future avenues of research are recommended for consideration: 
(1) The addition of pure nanoparticles into MQL cutting fluid has proven to be successful. Significant improvements were reported in energy consumption [102, 108], cutting and grinding forces [20, 103, 108], temperature [121], tool wear [21] and surface quality of the workpiece [21, 122]. Recently, a study was made involving a hybrid of nanoparticles, $\mathrm{MoS}_{2}$ and CNT, in a grinding experiment of nickel based alloy and it was shown that the addition of hybrid nanoparticles led to improved lubricity compared to either of the pure nanoparticle [123]. Therefore, the authors recommend the further investigation of hybrid nanoparticle additives.

(2) To improve the cooling effect of MQL, researchers have combined it with cooled air including CPMJ and RHVT, in addition to supercritical $\mathrm{CO}_{2}$, and have obtained promising results. From considering the available literature the authors have found great potential in the combination of MQL and RHVT. The authors favour this particular combination owing to the advantages of a vortex tube, namely, low cost, simple mechanism, maintenance free and the ready availability of compressed air. Therefore, the future investigation of end milling using MQL and RHVT is suggested by the authors due to turning having previously been the main focus.

(3) Additional research needs to be carried out for grinding as the use of MQL has been found to have conflicting reviews with respect to its effectiveness with soft materials.

(4) One final area of MQL that needs further consideration is the determination of the optimum operating conditions such as nozzle distance from workpiece, flow rate, angle of nozzle to the workpiece and operating pressure. 


\section{References}

[1] S. Amini, H. Khakbaz, and A. Barani, "Improvement of Near-Dry Machining and Its Effect on Tool Wear in Turning of AISI 4142”, Materials and Manufacturing Processes, vol. 30, pp. 241-247, 2015.

[2] V. P. Astakhov, "Ecological Machining: Near-dry Machining", in Machining, ed: Springer London, 2008, pp. 195-223.

[3] J. S. Dureja, R. Singh, T. Singh, P. Singh, M. Dogra, and M. Bhatti, "Performance evaluation of coated carbide tool in machining of stainless steel (AISI 202) under minimum quantity lubrication (MQL)", International Journal of Precision Engineering and Manufacturing-Green Technology, vol. 2, pp. 123-129, 2015.

[4] H. Tschätsch and A. Reichelt, "Cutting fluids (coolants and lubricants)", in Applied Machining Technology, ed: Springer Berlin Heidelberg, 2009, pp. 349-352.

[5] T. Obikawa, Y. Kamata, Y. Asano, K. Nakayama, and A. W. Otieno, "Micro-liter lubrication machining of Inconel 718”, International Journal of Machine Tools and Manufacture, vol. 48, pp. 1605-1612, 2008.

[6] V. S. Sharma, M. Dogra, and N. M. Suri, "Cooling techniques for improved productivity in turning”, International Journal of Machine Tools and Manufacture, vol. 49, pp. 435-453, 2009.

[7] B. L. Tai, D. A. Stephenson, R. J. Furness, and A. J. Shih, "Minimum Quantity Lubrication (MQL) in Automotive Powertrain Machining”, Procedia CIRP, vol. 14, pp. 523-528, 2014.

[8] L. M. Barczak, A. D. L. Batako, and M. N. Morgan, "A study of plane surface grinding under minimum quantity lubrication (MQL) conditions", International Journal of Machine Tools and Manufacture, vol. 50, pp. 977-985, 2010.

[9] S. Bhowmick, "Minimum quantity lubrication machining of aluminum and magnesium alloys", NR61929 Ph.D., University of Windsor (Canada), Ann Arbor, 2011.

[10] M. N. Morgan, L. Barczak, and A. Batako, "Temperatures in fine grinding with minimum quantity lubrication (MQL)", The International Journal of Advanced Manufacturing Technology, vol. 60, pp. 951-958, 2012.

[11] M. Weck and A. Koch, "Spindle bearing systems for high-speed applications in machine tools”, CIRP Annals - Manufacturing Technology, vol. 42(1), pp. 445-448, 1993.

[12] E. Brinkmeier, T. Brockoff and A. Walter, "Minimum quantity lubrication in grinding", Technical Paper - Society of Manufacturing Engineers, vol. 97(230), pp. X1-14, 1997.

[13] T. Brokoff and A. Walter, "Fluid minimization in cutting and grinding", Abrasives, October, pp. 38-42, 1998.

[14] Document search results for "minimum quantity lubrication", Scopus (www.scopus.com), Elsevier B.V., Amsterdam, The Netherlands (accessed November 16th 2016). 
[15] P. R. Huber and J. Werner, "On Minimum Oil Lubrication of Roller Bearings", Schmiertechnik + Tribologie, vol. 27, pp. 90-95, 1980.

[16] H. Schemmel, "Minimum Quantity Oil Lubrication of Roller Bearings", Schmiertechnik + Tribologie, vol. 27, pp. 193-196, 1980.

[17] H. Nakai, N. Ino, and H. Hashimoto, "Piston-ring lubrication problems for refrigeration compressors considering combined effects of supply oil quantity and surface roughness", Journal of Tribology, vol. 118, pp. 286-291, 1996.

[18] J. Sun, G. S. Liu, F. Xu, E. M. Miao, X. H. Song, L. Shu, et al., "Effect of the lubrication condition at entrance on the lubrication performance of piston ring-cylinder liner frictional pair”, Mocaxue Xuebao/Tribology, vol. 35, pp. 423-430, 2015.

[19] E. Brinksmeier, A. Walter, R. Jansson and P. Diersen, "Aspects of cooling lubrication reduction in machining advanced materials", Proceedings of the Institution of Mechanical Engineers, Part B: Journal of Engineering Manufacture, vol. 213(8), pp. 769-778, 1999.

[20] C. Mao, Y. Huang, X. Zhou, H. Gan, J. Zhang, and Z. Zhou, "The tribological properties of nanofluid used in minimum quantity lubrication grinding", The International Journal of Advanced Manufacturing Technology, vol. 71, pp. 1221-1228, 2014.

[21] A. Uysal, F. Demiren, and E. Altan, "Applying Minimum Quantity Lubrication (MQL) Method on Milling of Martensitic Stainless Steel by Using Nano Mos2 Reinforced Vegetable Cutting Fluid”, Procedia - Social and Behavioral Sciences, vol. 195, pp. 2742-2747, 2015.

[22] H. Salaam, Z. B. Taha, T. M. Y. Shah, and T. Ya, "Minimum Quantity Lubrication (MQL) Using Ranque - Hilsch Vortex Tube (RHVT) for Sustainable Machining”, Applied Mechanics and Materials, vol. 217-219, p. 2012, Nov 2012

[23] D.N. Rao, R.R. Srikant, P.V. Krishna and M.S. Subrahmanyam, "Nano cutting fluids in minimum quantity lubrication", in Proceedings of the International Multi-Conference on Engineering and Technological Innovation (IMETI), vol. 1, pp. 60-63, Orlando, U.S.A., 2008

[24] N. Narutaki, Y. Yamane, S. Tashima and H. Kuroki, "A New Advanced Ceramic for Dry Machining", Annals of the CIRP, Vol. 16, No. 1, pp. 43-48, 1997.

[25] C. Granger, "Dry machining's double benefit", Machinery and Production Engineering, Vol. 152, pp. 14-20, 1994.

[26] S. C. Feng and M. Hattori, "Cost and Process Information Modeling for Dry Machining”, Proceedings of the International Workshops for Environment Conscious Machining - ICEM 2000, p. 7, 2000.

[27] N. Boubekri, V. Shaikh, and P. R. Foster, "A technology enabler for green machining: minimum quantity lubrication (MQL)", Journal of Manufacturing Technology Management, vol. 21, pp. 556-566, 2010

[28] F. Klocke and G. Eisenblätter, "Dry Cutting", CIRP Annals - Manufacturing Technology, vol. 46, pp. 519-526, 1997. 
[29] S. Hinduja, Proceedings of the 34th International MATADOR Conference: Formerly The International Machine Tool Design and Research Conferences: Springer London, 2004.

[30] C. Freiler, D. Hörner, W. Buss, F. Kubicki, A. Losch, and T. Mang, "Lubricants, 7. Metalworking Fluids and Forming Lubricants", in Ullmann's Encyclopedia of Industrial Chemistry, ed: Wiley-VCH Verlag GmbH \& Co. KGaA, 2000.

[31] G. Landgraf. (2004, January 2004) Dry Goods. Cutting Tool Engineering. 4. Available: http://unist.com/pdfs/articles/Dry_Goods.pdf

[32] P. S. Sreejith and B. K. A. Ngoi, "Dry Machining: Machining of The Future", Journal of Materials Processing Technology, vol. 101, pp. 287-291, 2000.

[33] M. N. Islam and B. Boswell, "An investigation of surface finish in dry turning", in Proceedings of the World Congress on Engineering, 2011, pp. 6-8.

[34] D. Dudzinski, A. Devillez, A. Moufki, D. Larrouquère, V. Zerrouki, and J. Vigneau, "A review of developments towards dry and high speed machining of Inconel 718 alloy", International Journal of Machine Tools and Manufacture, vol. 44, pp. 439-456, 2004.

[35] M. Kutz, Environmentally Conscious Manufacturing: Wiley, 2007.

[36] J. M. Dasch, C. C. Ang, C. A. Wong, Y. T. Cheng, A. M. Weiner, L. C. Lev, et al., "A comparison of five categories of carbon-based tool coatings for dry drilling of aluminum", Surface and Coatings Technology, vol. 200, pp. 2970-2977, 2006.

[37] M. Hadad and M. Hadi, "An investigation on surface grinding of hardened stainless steel S34700 and aluminum alloy AA6061 using minimum quantity of lubrication (MQL) technique", The International Journal of Advanced Manufacturing Technology, vol. 68, pp. 2145-2158, 2013.

[38] U. S. Dixit, D. K. Sarma, and J. P. Davim, "Machining with Minimal Cutting Fluid", in Environmentally Friendly Machining, ed: Springer US, 2012, pp. 9-17.

[39] S. Debnath, M. M. Reddy, and Q. S. Yi, "Environmental friendly cutting fluids and cooling techniques in machining: a review”, Journal of Cleaner Production, vol. 83, pp. 33-47, 2014.

[40] M. M. A. Khan and N. R. Dhar, "Performance evaluation of minimum quantity lubrication by vegetable oil in terms of cutting force, cutting zone temperature, tool wear, job dimension and surface finish in turning AISI-1060 steel", Journal of Zhejiang University SCIENCE A, vol. 7, pp. 1790-1799, 2006.

[41] W. Sales, M. Becker, C. S. Barcellos, J. L. Jr, J. Bonney, and E. O. Ezugwu, "Tribological behaviour when face milling AISI 4140 steel with minimum quantity fluid application”, Industrial Lubrication and Tribology, vol. 61, pp. 84-90, 2009.

[42] E. A. Rahim and H. Sasahara, "High Speed MQL Drilling of Titanium Alloy using Synthetic Ester and Palm Oil”, in Proceedings of the 36th International MATADOR Conference, S. Hinduja and L. Li, Eds., ed: Springer London, 2010, pp. 193-196. 
[43] W. Belluco and L. De Chiffre, "Performance evaluation of vegetable-based oils in drilling austenitic stainless steel”, Journal of Materials Processing Technology, vol. 148, pp. 171-176, 2004.

[44] Y. R. Ginting, B. Boswell, W. Biswas, and N. Islam, "Advancing Environmentally Conscious Machining”, Procedia CIRP, vol. 26, pp. 391-396, 2015.

[45] M. N. Islam, "Effect of Additional Factors on Dimensional Accuracy and Surface Finish of Turned Parts”, Machining Science and Technology, vol. 17, pp. 145-162, 2013.

[46] S. M. Alves and J. F. G. d. Oliveira, "Vegetable based cutting fluid - an environmental alternative to grinding process", presented at the 15th CIRP International Conference on Life Cycle Engineering, Sydney, 2008.

[47] M. V. Ramana, G. K. M. Rao, and D. H. Rao, "Experimental Investigations And Selection Of Optimal Cutting Conditions In Turning Of Ti-6Al-4V Alloy With Different Cutting Fluids By Minimum Quantity Lubrication (MQL) Methodology", i-Manager's Journal on Mechanical Engineering, vol. 2, pp. 45-52, 2011.

[48] M. H. Sadeghi, M. J. Haddad, T. Tawakoli, and M. Emami, "Minimal quantity lubricationMQL in grinding of Ti-6Al-4V titanium alloy", The International Journal of Advanced Manufacturing Technology, vol. 44, pp. 487-500, 2009.

[49] B. Tasdelen, T. Wikblom, and S. Ekered, "Studies on minimum quantity lubrication (MQL) and air cooling at drilling", Journal of Materials Processing Technology, vol. 200, pp. 339346, 2008.

[50] A. Braghini Junior, A. Diniz, and F. Filho, "Tool wear and tool life in end milling of 15-5 PH stainless steel under different cooling and lubrication conditions", The International Journal of Advanced Manufacturing Technology, vol. 43, pp. 756-764, 2009.

[51] Y. Su, N. He, and L. Li, "Effect of Cryogenic Minimum Quantity Lubrication (CMQL) on Cutting Temperature and Tool Wear in High-Speed End Milling of Titanium Alloys", Applied Mechanics and Materials, vol. 34-35, p. 1816, 2010

[52] S. Kurgin, J. M. Dasch, D. L. Simon, G. C. Barber, and Q. Zou, "A comparison of two minimum quantity lubrication delivery systems”, Industrial Lubrication and Tribology, vol. 66, pp. 151-159, 2014

[53] R. P. Zeilmann and W. L. Weingaertner, "Analysis of temperature during drilling of Ti6A14V with minimal quantity of lubricant”, Journal of Materials Processing Technology, vol. 179, pp. 124-127, 2006.

[54] E. Brinksmeier and R. Janssen, "Drilling of Multi-Layer Composite Materials consisting of Carbon Fiber Reinforced Plastics (CFRP), Titanium and Aluminum Alloys”, CIRP Annals Manufacturing Technology, vol. 51, pp. 87-90, 2002.

[55] E. Brinksmeier, O. Pecat, and R. Rentsch, "Quantitative analysis of chip extraction in drilling of Ti6Al4V", CIRP Annals - Manufacturing Technology. 
[56] P. S. Sreejith, "Machining of 6061 aluminium alloy with MQL, dry and flooded lubricant conditions", Materials Letters, vol. 62, pp. 276-278, 2008.

[57] H. Yoshimura, T. Moriwaki, N. Ohmae, T. Nakai, T. Shibasaka, H. Kinoshita, et al., "Study on Near Dry Machining of Aluminum Alloys", JSME International Journal Series C Mechanical Systems, Machine Elements and Manufacturing, vol. 49, pp. 83-89, 2006.

[58] J. Yan, Y. Murakami, and J. P. Davim, “Tool Design, Tool Wear and Tool Life”, in Machining Dynamics, K. Cheng, Ed., ed: Springer London, 2009, pp. 117-149.

[59] C. C. Tsao, "An experiment study of hard coating and cutting fluid effect in milling aluminum alloy", The International Journal of Advanced Manufacturing Technology, vol. 32, pp. 885$891,2007$.

[60] L. N. L. d. Lacalle, A. Lamikiz, J. A. Sanchez, and I. Cabanes, "Cutting conditions and tool optimization in the high-speed milling of aluminium alloys", Proceedings of the Institution of Mechanical Engineers, vol. 215, p. 1257, 2001

[61] V. Diciuc, M. Lobontiu, G. Bran, and V. Lazar, "The Influence of the Lubrication Method and the Cutting Regime on the Surface Roughness when Milling 7175 Aluminum Alloy”, Applied Mechanics and Materials, vol. 371, p. 28, 2013

[62] H. Sohrabpoor, S. Khanghah, and R. Teimouri, "Investigation of lubricant condition and machining parameters while turning of AISI 4340", The International Journal of Advanced Manufacturing Technology, vol. 76, pp. 2099-2116, 2015.

[63] N. R. Dhar, M. W. Islam, S. Islam, and M. A. H. Mithu, "The influence of minimum quantity of lubrication (MQL) on cutting temperature, chip and dimensional accuracy in turning AISI1040 steel”, Journal of Materials Processing Technology, vol. 171, pp. 93-99, 2006.

[64] N. R. Dhar, M. T. Ahmed, and S. Islam, “An experimental investigation on effect of minimum quantity lubrication in machining AISI 1040 steel”, International Journal of Machine Tools and Manufacture, vol. 47, pp. 748-753, 2007.

[65] N. R. Dhar, M. Kamruzzaman, and M. Ahmed, "Effect of minimum quantity lubrication (MQL) on tool wear and surface roughness in turning AISI-4340 steel", Journal of Materials Processing Technology, vol. 172, pp. 299-304, 2006.

[66] M. Rahman, A. Senthil Kumar, and M. U. Salam, "Experimental evaluation on the effect of minimal quantities of lubricant in milling", International Journal of Machine Tools and Manufacture, vol. 42, pp. 539-547, 2002.

[67] L. C. da Silva, P. R. da Mota, M. B. da Silva, E. O. Ezugwu, and Á. R. Machado, "Study of burr behavior in face milling of PH 13-8 Mo stainless steel", CIRP Journal of Manufacturing Science and Technology, vol. 8, pp. 34-42, 2015.

[68] P. C. Priarone, M. Robiglio, L. Settineri, and V. Tebaldo, "Milling and Turning of Titanium Aluminides by Using Minimum Quantity Lubrication”, Procedia CIRP, vol. 24, pp. 62-67, 2014. 
[69] A. Aryasomayajula and U. o. Arkansas, Low Temperature Alpha Alumina Thin Film Coating for Cutting Tool Application by AC Inverted Magnetron Sputtering Technique: University of Arkansas, 2008.

[70] D. Graham, "Turning difficult-to-machine alloys", Modern Machine Shop, vol. 75, p. 92, 2002

[71] J. Lorincz, "The Heat Is On Difficult-to-Machine Metals", Manufacturing Engineering, vol. 154, pp. 55-64, 2015

[72] A. Pramanik and G. Littlefair, "Machining of titanium alloy (Ti-6Al-4V)-theory to application", Machining Science and Technology, vol. 19, pp. 1-49, 2015.

[73] K.-H. Park, G.-D. Yang, M.-G. Lee, H. Jeong, S.-W. Lee, and D. Lee, "Eco-friendly face milling of titanium alloy", International Journal of Precision Engineering and Manufacturing, vol. 15, pp. 1159-1164, 2014.

[74] Z. G. Wang, M. Rahman, Y. S. Wong, K. S. Neo, J. Sun, C. H. Tan, et al., "Study on orthogonal turning of titanium alloys with different coolant supply strategies", The International Journal of Advanced Manufacturing Technology, vol. 42, pp. 621-632, 2009.

[75] B. Boswell and M. N. Islam, "Sustainable cooling method for machining titanium alloy", IOP Conference Series: Materials Science and Engineering, vol. 114, p. 012021, 2016.

[76] (2014, May 13). MONEL alloy K-500 Marine Alloy QQ-N-286(UNS N05500) Ni 65.5 Cu 29.5 $\mathrm{Al} \quad 2.7, \quad \mathrm{Ti} \quad 0.6 \quad$ Description $\quad$ [Online]. Available: http://www.hpalloy.com/Alloys/descriptions/MONELK_500.aspx

[77] N. Javam, "The Study of High Speed Turning Using MQL", Indian Journal of Science and Technology, vol. 6, pp. 4123-4127, 2013

[78] J. Sharma and B. S. Sidhu, "Investigation of effects of dry and near dry machining on AISI D2 steel using vegetable oil", Journal of Cleaner Production, vol. 66, pp. 619-623, 2014.

[79] T. Beno, M. Isaksson, and L. Pejryd, "Investigation of Minimal Quantity Lubrication in Turning of Waspaloy", in Advances in Life Cycle Engineering for Sustainable Manufacturing Businesses, S. Takata and Y. Umeda, Eds., ed: Springer London, 2007, pp. 305-310.

[80] R. S. H. S. Thamizhmanii, “A Study of Minimum Quantity Lubrication on Inconel 718 Steel”, International Scientific Journal, vol. 39, pp. 38-44, 2009.

[81] S. Bhowmick and A. T. Alpas, "Minimum quantity lubrication drilling of aluminium-silicon alloys in water using diamond-like carbon coated drills", International Journal of Machine Tools and Manufacture, vol. 48, pp. 1429-1443, 2008.

[82] G. Fox-Rabinovich, J. M. Dasch, T. Wagg, K. Yamamoto, S. Veldhuis, G. K. Dosbaeva, et al., "Cutting performance of different coatings during minimum quantity lubrication drilling of aluminum silicon B319 cast alloy”, Surface and Coatings Technology, vol. 205, pp. 41074116, 2011. 
[83] J. P. Davim, P. S. Sreejith, R. Gomes, and C. Peixoto, "Experimental studies on drilling of aluminium (AA1050) under dry, minimum quantity of lubricant, and flood-lubricated conditions", Proceedings of the Institution of Mechanical Engineers B, Journal of Engineering Manufacture, vol. 220, pp. 1605-1611, 2006.

[84] D. U. Braga, A. E. Diniz, G. W. A. Miranda, and N. L. Coppini, "Using a minimum quantity of lubricant (MQL) and a diamond coated tool in the drilling of aluminum-silicon alloys", Journal of Materials Processing Technology, vol. 122, pp. 127-138, 2002.

[85] R. U. Shingarwade and P. S. Chavan, "A review on MQL in reaming”, International Journal of Mechanical Engineering and Robotics Research, vol. 3, pp. 392-398, 2014

[86] R. Zeilmann, G. Nicola, T. Vacaro, C. Teixeira, and R. Heiler, "Implications of the reduction of cutting fluid in drilling AISI P20 steel with carbide tools", The International Journal of Advanced Manufacturing Technology, vol. 58, pp. 431-441, 2012.

[87] R. Heinemann, S. Hinduja, G. Barrow, and G. Petuelli, "Effect of MQL on the tool life of small twist drills in deep-hole drilling", International Journal of Machine Tools and Manufacture, vol. 46, pp. 1-6, 2006.

[88] A. Meena and M. El Mansori, "Study of dry and minimum quantity lubrication drilling of novel austempered ductile iron (ADI) for automotive applications", Wear, vol. 271, pp. 24122416, 2011.

[89] A. Di Ilio, A. Paoletti, V. Tagliaferri, and F. Veniali, "An experimental study on grinding of silicon carbide reinforced aluminium alloys", International Journal of Machine Tools and Manufacture, vol. 36, pp. 673-685, 1996.

[90] J. R. Davis, J. R. D. Associates, and A. S. M. I. H. Committee, Aluminum and Aluminum Alloys: ASM International, 1993.

[91] M. N. Islam, A. Pramanik, A. Basak, and G. Littlefair, "Machining and Tool Wear Mechanisms during Machining Titanium Alloys", 2013.

[92] S. X. Yuan and B. Bi, "Experimental Study on the Belt Grinding Mechanism for Aluminum Alloys", Applied Mechanics and Materials, vol. 16-19, p. 60, 2009

[93] M. Hadad and B. Sadeghi, "Thermal analysis of minimum quantity lubrication-MQL grinding process", International Journal of Machine Tools and Manufacture, vol. 63, pp. 1-15, 2012.

[94] Y. Shao, O. Fergani, B. Li, and S. Liang, "Residual stress modeling in minimum quantity lubrication grinding”, The International Journal of Advanced Manufacturing Technology, pp. $1-9,2015$.

[95] C. Mao, X. Tang, H. Zou, Z. Zhou, and W. Yin, "Experimental investigation of surface quality for minimum quantity oil-water lubrication grinding", The International Journal of Advanced Manufacturing Technology, vol. 59, pp. 93-100, 2012. 
[96] M. J. Hadad, T. Tawakoli, M. H. Sadeghi, and B. Sadeghi, "Temperature and energy partition in minimum quantity lubrication-MQL grinding process", International Journal of Machine Tools and Manufacture, vol. 54-55, pp. 10-17, 2012.

[97] “Grinding Difficult Materials”, Manufacturing Engineering, vol. 146, pp. 71-77, Feb 2011

[98] D. Setti, S. Ghosh, and P. V. Rao, "Application of Nano Cutting Fluid under Minimum Quantity Lubrication (MQL) Technique to Improve Grinding of Ti - 6Al - 4V Alloy", Çanakkale, 2012, pp. 512-516.

[99] Q. An, Y. Fu, and J. Xu, "A new technology on enhancing heat transfer during grinding of titanium alloy", Industrial Lubrication and Tribology, vol. 62, pp. 168-173, 2010

[100] M. Gupta, G. Singh, and P. Sood, "Experimental Investigation of Machining AISI 1040 Medium Carbon Steel Under Cryogenic Machining: A Comparison with Dry Machining”, Journal of The Institution of Engineers (India): Series C, vol. 96, pp. 373-379, 2015.

[101] H. Tönshoff and B. Denkena, "Cooling Lubrication", in Basics of Cutting and Abrasive Processes, ed: Springer Berlin Heidelberg, 2013, pp. 371-396.

[102] P. Kalita, A. P. Malshe, S. Arun Kumar, V. G. Yoganath, and T. Gurumurthy, "Study of specific energy and friction coefficient in minimum quantity lubrication grinding using oilbased nanolubricants”, Journal of Manufacturing Processes, vol. 14, pp. 160-166, 2012.

[103] P. Kalita, A. P. Malshe, and K. P. Rajurkar, "Study of tribo-chemical lubricant film formation during application of nanolubricants in minimum quantity lubrication (MQL) grinding”, CIRP Annals - Manufacturing Technology, vol. 61, pp. 327-330, 2012.

[104] B. Davis, J. K. Schueller, and Y. Huang, "Study of ionic liquid as effective additive for minimum quantity lubrication during titanium machining", Manufacturing Letters, vol. 5, pp. $1-6,2015$.

[105] G. S. Goindi, S. N. Chavan, D. Mandal, P. Sarkar, and A. D. Jayal, "Investigation of Ionic Liquids as Novel Metalworking Fluids during Minimum Quantity Lubrication Machining of a Plain Carbon Steel”, Procedia CIRP, vol. 26, pp. 341-345, 2015.

[106] M.-Q. Pham, H.-S. Yoon, V. Khare, and S.-H. Ahn, "Evaluation of ionic liquids as lubricants in micro milling - process capability and sustainability", Journal of Cleaner Production, vol. 76, pp. 167-173, 2014.

[107] P. Krajnik, F. Pusavec, and A. Rashid, "Nanofluids: Properties, Applications and Sustainability Aspects in Materials Processing Technologies", in Advances in Sustainable Manufacturing, G. Seliger, M. M. K. Khraisheh, and I. S. Jawahir, Eds., ed: Springer Berlin Heidelberg, 2011, pp. 107-113.

[108] D. Zhang, C. Li, Y. Zhang, D. Jia, and X. Zhang, "Experimental research on the energy ratio coefficient and specific grinding energy in nanoparticle jet MQL grinding”, The International Journal of Advanced Manufacturing Technology, vol. 78, pp. 1275-1288, 2015. 
[109] M. Hemmat Esfe, A. Karimipour, W.-M. Yan, M. Akbari, M. R. Safaei, and M. Dahari, "Experimental study on thermal conductivity of ethylene glycol based nanofluids containing $\mathrm{Al}_{2} \mathrm{O}_{3}$ nanoparticles", International Journal of Heat and Mass Transfer, vol. 88, pp. 728-734, 2015 .

[110] L. Fedele, L. Colla, and S. Bobbo, "Viscosity and thermal conductivity measurements of water-based nanofluids containing titanium oxide nanoparticles", International Journal of Refrigeration, vol. 35, pp. 1359-1366, 2012.

[111] M. Arulprakasajothi, K. Elangovan, K. H. Reddy, and S. Suresh, "Heat Transfer Study of Water-based Nanofluids Containing Titanium Oxide Nanoparticles", Materials Today: Proceedings, vol. 2, pp. 3648-3655, 2015.

[112] X. Li, C. Zou, X. Lei, and W. Li, "Stability and enhanced thermal conductivity of ethylene glycol-based SiC nanofluids", International Journal of Heat and Mass Transfer, vol. 89, pp. 613-619, 2015.

[113] A. Karimi, M. A. A. Sadatlu, B. Saberi, H. Shariatmadar, and M. Ashjaee, "Experimental investigation on thermal conductivity of water based nickel ferrite nanofluids", Advanced Powder Technology.

[114] W. Yu, H. Xie, Y. Li, L. Chen, and Q. Wang, "Experimental investigation on the thermal transport properties of ethylene glycol based nanofluids containing low volume concentration diamond nanoparticles", Colloids and Surfaces A: Physicochemical and Engineering Aspects, vol. 380, pp. 1-5, 2011.

[115] D. X. Peng, Y. Kang, R. M. Hwang, S. S. Shyr, and Y. P. Chang, "Tribological properties of diamond and $\mathrm{SiO} 2$ nanoparticles added in paraffin", Tribology International, vol. 42, pp. 911917, 2009.

[116] Z. Tang and S. Li, "A review of recent developments of friction modifiers for liquid lubricants (2007-present)", Current Opinion in Solid State and Materials Science, vol. 18, pp. 119-139, 2014.

[117] A. K. Sharma, A. K. Tiwari, and A. R. Dixit, "Mechanism of Nanoparticles Functioning and Effects in Machining Processes: A Review”, Materials Today: Proceedings, vol. 2, pp. 35393544, 2015.

[118] H. Xie, B. Jiang, J. He, X. Xia, and F. Pan, "Lubrication performance of MoS2 and SiO2 nanoparticles as lubricant additives in magnesium alloy-steel contacts", Tribology International.

[119] D. Jiao, S. Zheng, Y. Wang, R. Guan, and B. Cao, "The tribology properties of alumina/silica composite nanoparticles as lubricant additives”, Applied Surface Science, vol. 257, pp. 5720$5725,2011$. 
[120] L. Peña-Parás, J. Taha-Tijerina, L. Garza, D. Maldonado-Cortés, R. Michalczewski, and C. Lapray, "Effect of $\mathrm{CuO}$ and $\mathrm{Al} 2 \mathrm{O} 3$ nanoparticle additives on the tribological behavior of fully formulated oils", Wear, vol. 332-333, pp. 1256-1261, 2015.

[121] Y. Su, L. Gong, B. Li, Z. Liu, and D. Chen, "Performance evaluation of nanofluid MQL with vegetable-based oil and ester oil as base fluids in turning", The International Journal of Advanced Manufacturing Technology, pp. 1-7, 2015.

[122] B. Rahmati, A. A. D. Sarhan, and M. Sayuti, "Morphology of surface generated by end milling AL6061-T6 using molybdenum disulfide (MoS2) nanolubrication in end milling machining", Journal of Cleaner Production, vol. 66, pp. 685-691, 2014.

[123] Y. Zhang, C. Li, D. Jia, D. Zhang, and X. Zhang, "Experimental evaluation of the lubrication performance of MoS2/CNT nanofluid for minimal quantity lubrication in Ni-based alloy grinding", International Journal of Machine Tools and Manufacture, vol. 99, pp. 19-33, 2015.

[124] C. Buzea, I. Pacheco, and K. Robbie, "Nanomaterials and nanoparticles: Sources and toxicity”, Biointerphases, vol. 2, pp. MR17-MR71, 2007.

[125] A. Elsaesser and C. V. Howard, "Toxicology of nanoparticles”, Advanced Drug Delivery Reviews, vol. 64, pp. 129-137, 2012.

[126] D. A. Chaturvedi, D. P. Jain, and D. S. Malik, "Study of Nano Technology Based Solid Lubricant", vol. 3, pp. 31-32, 2012.

[127] “Nanotechnology Work Health \& Safety”, E. Australia, Ed., ed. Australia, 2013.

[128] S. H. Seyedmahmoudi, S. Harper, M. Weismiller, and K. Haapala, "Evaluating the use of zinc oxide and titanium dioxide nanoparticles in a metalworking fluid from a toxicological perspective", Journal of Nanoparticle Research, vol. 17, pp. 1-12, 2015.

[129] H. Kamimura, T. Kubo, I. Minami, and S. Mori, "Effect and mechanism of additives for ionic liquids as new lubricants”, Tribology International, vol. 40, pp. 620-625, 2007.

[130] M. Cai, Z. Zhao, Y. Liang, F. Zhou, and W. Liu, "Alkyl Imidazolium Ionic Liquids as Friction Reduction and Anti-Wear Additive in Polyurea Grease for Steel/Steel Contacts”, Tribology Letters, vol. 40, pp. 215-224, 2010.

[131] A. H. Battez, R. González, J. L. Viesca, D. Blanco, E. Asedegbega, and A. Osorio, "Tribological behaviour of two imidazolium ionic liquids as lubricant additives for steel/steel contacts", Wear, vol. 266, pp. 1224-1228, 2009.

[132] A. E. Jiménez, M. D. Bermúdez, F. J. Carrión, and G. Martínez-Nicolás, "Room temperature ionic liquids as lubricant additives in steel-aluminium contacts: Influence of sliding velocity, normal load and temperature", Wear, vol. 261, pp. 347-359, 2006.

[133] A.-E. Jiménez and M.-D. Bermúdez, "Imidazolium ionic liquids as additives of the synthetic ester propylene glycol dioleate in aluminium-steel lubrication”, Wear, vol. 265, pp. 787-798, 2008. 
[134] Y. Han, D. Qiao, L. Zhang, and D. Feng, "Study of tribological performance and mechanism of phosphonate ionic liquids for steel/aluminum contact", Tribology International, vol. 84, pp. 71-80, 2015.

[135] A. Jiménez and M.-D. Bermúdez, "Ionic Liquids as Lubricants of Titanium-Steel Contact", Tribology Letters, vol. 33, pp. 111-126, 2009.

[136] A. E. Jiménez and M. D. Bermúdez, "Ionic Liquids as Lubricants of Titanium-Steel Contact. Part 2: Friction, Wear and Surface Interactions at High Temperature", Tribology Letters, vol. 37, pp. 431-443, 2010.

[137] A. Libardi, S. R. Schmid, M. Sen, and W. Schneider, "Evaluation of ionic fluids as lubricants in manufacturing", Journal of Manufacturing Processes, vol. 15, pp. 414-418, 2013.

[138] S. Keskin, D. Kayrak-Talay, U. Akman, and Ö. Hortaçsu, "A review of ionic liquids towards supercritical fluid applications", The Journal of Supercritical Fluids, vol. 43, pp. 150-180, 2007.

[139] R. F. M. Frade and C. A. M. Afonso, "Impact of ionic liquids in environment and humans: An overview”, Human and Experimental Toxicology, vol. 29, pp. 1038-54, 2010

[140] E. Mulkiewicz and P. Stepnowski, "Recent developments in ionic liquid toxicity assessment", International Journal of Cognitive Linguistics, vol. 13, pp. 391-428, 2014

[141] P. Stepnowski, A. C. Skladanowski, A. Ludwiczak, and E. Laczynska, "Evaluating the cytotoxicity of ionic liquids using human cell line HeLa”, Hum Exp Toxicol, vol. 23, pp. 5137, 2004.

[142] J. Ranke, S. Stolte, R. Stormann, J. Arning, and B. Jastorff, "Design of sustainable chemical products--the example of ionic liquids", Chem Rev, vol. 107, pp. 2183-206, 2007.

[143] K. J. Kulacki, "Proactive aquatic ecotoxicology: A hazard assessment of room-temperature ionic liquids”, 3436462 Ph.D., University of Notre Dame, Ann Arbor, 2009.

[144] U. Heisel, M. Schaal, and G. Wolf, "Influence of Minimum Quantity Lubrication on Burr Formation in Milling”, in Burrs - Analysis, Control and Removal, J. C. Aurich and D. Dornfeld, Eds., ed: Springer Berlin Heidelberg, 2010, pp. 139-146.

[145] P. Faverjon, J. Rech, F. Valiorgue, and M. Orset, "Optimization of a drilling sequence under MQL to minimize the thermal distortion of a complex aluminum part", Production Engineering, vol. 9, pp. 505-515, 2015.

[146] D. A. Stephenson, S. J. Skerlos, A. S. King, and S. D. Supekar, "Rough turning Inconel 750 with supercritical CO2-based minimum quantity lubrication", Journal of Materials Processing Technology, vol. 214, pp. 673-680, 2014.

[147] B. Boswell and M. Islam, "The Challenge of Adopting Minimal Quantities of Lubrication for End Milling Aluminium”, in IAENG Transactions on Engineering Technologies. vol. 229, G.-C. Yang, S.-1. Ao, and L. Gelman, Eds., ed: Springer Netherlands, 2013, pp. 713-724. 
[148] V. Kırmac1, "Exergy analysis and performance of a counter flow Ranque-Hilsch vortex tube having various nozzle numbers at different inlet pressures of oxygen and air”, International Journal of Refrigeration, vol. 32, pp. 1626-1633, 2009.

[149] T. Dutta, K. P. Sinhamahapatra, and S. S. Bandyopdhyay, "Comparison of different turbulence models in predicting the temperature separation in a Ranque-Hilsch vortex tube", International Journal of Refrigeration, vol. 33, pp. 783-792, 2010.

[150] M. Selek, S. Tasdemir, K. Dincer, and S. Baskaya, "Experimental examination of the cooling performance of Ranque-Hilsch vortex tube on the cutting tool nose point of the turret lathe through infrared thermography method", International Journal of Refrigeration, vol. 34, pp. 807-815, 2011.

[151] A. Mohamad, N. A. M. Amin, Z. M. Razlan, and M. S. A. Majid, "Experimental Studies of a Ranque-Hilsch Vortex Tube", Applied Mechanics and Materials, vol. 390, p. 670, 2013

[152] K. Dincer, S. Tasdemir, S. Baskaya, and B. Z. Uysal, "Modeling of the effects of length to diameter ratio and nozzle number on the performance of counterflow Ranque-Hilsch vortex tubes using artificial neural networks”, Applied Thermal Engineering, vol. 28, pp. 2380-2390, 2008.

[153] N. Agrawal, S. S. Naik, and Y. P. Gawale, "Experimental investigation of vortex tube using natural substances", International Communications in Heat and Mass Transfer, vol. 52, pp. $51-55,3 / / 2014$.

[154] B. Yalçın, A. E. Özgür, and M. Koru, "The effects of various cooling strategies on surface roughness and tool wear during soft materials milling”, Materials \& Design, vol. 30, pp. 896899, 2009.

[155] J. Liu and Y. Kevin Chou, "On temperatures and tool wear in machining hypereutectic Al-Si alloys with vortex-tube cooling", International Journal of Machine Tools and Manufacture, vol. 47, pp. 635-645, 2007.

[156] R. T. Balmer, "Pressure-Driven Ranque-Hilsch Temperature Separation in Liquids", Journal of Fluids Engineering, vol. 110, pp. 161-164, 1988.

[157] S. A. Chowdhury, M. N. Islam, and B. Boswell, "Predicting the Influence of the Machining Parameters on the Tool Tip Temperature", in Transactions on Engineering Technologies, G.C. Yang, S.-I. Ao, and L. Gelman, Eds., ed: Springer Netherlands, 2015, pp. 305-316.

[158] S. Zhang, J. Li, and H. Lv, "Tool Wear and Formation Mechanism of White Layer When Hard Milling H13 Steel under Different Cooling/Lubrication Conditions", Advances in Mechanical Engineering, 2014.

[159] Y. Su, N. He, L. Li, A. Iqbal, M. H. Xiao, S. Xu, et al., "Refrigerated cooling air cutting of difficult-to-cut materials", International Journal of Machine Tools and Manufacture, vol. 47, pp. 927-933, 2007. 
[160] S. Ravi and M. Pradeep Kumar, "Experimental investigations on cryogenic cooling by liquid nitrogen in the end milling of hardened steel", Cryogenics, vol. 51, pp. 509-515, 2011.

[161] X. Huang, X. Zhang, H. Mou, X. Zhang, and H. Ding, "The influence of cryogenic cooling on milling stability”, Journal of Materials Processing Technology, vol. 214, pp. 3169-3178, 2014.

[162] N. R. Dhar, S. V. Nanda Kishore, S. Paul, and A. B. Chattopadhyay, "The effects of cryogenic cooling on chips and cutting forces in turning AISI 1040 and AISI 4320 steels", Proceedings of the Institution of Mechanical Engineers, vol. 216, p. 713, 2002

[163] K. A. Venugopal, R. Tawade, P. G. Prashanth, S. Paul, and A. B. Chattopadhyay, "Turning of titanium alloy with $\mathrm{TiB}^{\wedge} \mathrm{sub} 2^{\wedge}$-coated carbides under cryogenic cooling”, Proceedings of the Institution of Mechanical Engineers, vol. 217, pp. 1697-1707, 2003

[164] M. Dix, R. Wertheim, G. Schmidt, and C. Hochmuth, "Modeling of drilling assisted by cryogenic cooling for higher efficiency", CIRP Annals - Manufacturing Technology, vol. 63, pp. 73-76, 2014.

[165] G. Manimaran, M. Pradeep kumar, and R. Venkatasamy, "Influence of cryogenic cooling on surface grinding of stainless steel 316", Cryogenics, vol. 59, pp. 76-83, 2014.

[166] S. M. Yuan, L. T. Yan, W. D. Liu, and Q. Liu, "Effects of cooling air temperature on cryogenic machining of Ti-6Al-4V alloy”, Journal of Materials Processing Technology, vol. 211, pp. 356-362, 2011.

[167] L. T. Zou, S. Zhang, and Q. Zhang, "Computer Fluid Dynamics Analysis of Cryogenic Oil Mist and Structural Optimization of Spraying Nozzle", Applied Mechanics and Materials, vol. 241-244, p. 1310, 2012

[168] J. A. Sanchez, I. Pombo, R. Alberdi, B. Izquierdo, N. Ortega, S. Plaza, et al., "Machining evaluation of a hybrid MQL-CO2 grinding technology", Journal of Cleaner Production, vol. 18, pp. 1840-1849, 2010.

[169] E. García, D. Méresse, I. Pombo, M. Dubar, and J. A. Sánchez, "Role of frozen lubricant film on tribological behaviour and wear mechanisms in grinding", The International Journal of Advanced Manufacturing Technology, pp. 1-11, 2015.

[170] A. F. Clarens, K. F. Hayes, and S. J. Skerlos, "Feasibility of Metalworking Fluids Delivered in Supercritical Carbon Dioxide”, Journal of Manufacturing Processes, vol. 8, pp. 47-53, 2006

[171] “Greenhouse Gases”, P. o. Australia, Ed., ed. Australua, 2008.

[172] T. T. Mon, J. Ramli, A. R. Jeefferie, S. Sharif, and V. C. Venkatesh, "Performance of Cryogenic Machining with Nitrogen Gas in Machining of Titanium”, Applied Mechanics and Materials, vol. 52-54, p. 2003, 2011

[173] D. Lozowski, "Supercritical $\mathrm{CO}_{2}$ : A green solvent", Chemical Engineering, vol. 117, pp. 1518,2010 
[174] S. D. Supekar, A. F. Clarens, D. A. Stephenson, and S. J. Skerlos, "Performance of supercritical carbon dioxide sprays as coolants and lubricants in representative metalworking operations”, Journal of Materials Processing Technology, vol. 212, pp. 2652-2658, 2012.

[175] T. Ekvall and B. Weidema, "System boundaries and input data in consequential life cycle inventory analysis”, The International Journal of Life Cycle Assessment, vol. 9, pp. 161-171, 